University of Louisville

ThinkIR: The University of Louisville's Institutional Repository

\title{
An analysis of teacher efficacy, resident efficacy, and teacher- student relationships with behaviorally challenged youth in residential treatment settings.
}

Andrew J. Nichols

University of Louisville

Follow this and additional works at: https://ir.library.louisville.edu/etd

\section{Recommended Citation}

Nichols, Andrew J., "An analysis of teacher efficacy, resident efficacy, and teacher-student relationships with behaviorally challenged youth in residential treatment settings." (2011). Electronic Theses and Dissertations. Paper 1059.

https://doi.org/10.18297/etd/1059

This Doctoral Dissertation is brought to you for free and open access by ThinkIR: The University of Louisville's Institutional Repository. It has been accepted for inclusion in Electronic Theses and Dissertations by an authorized administrator of ThinkIR: The University of Louisville's Institutional Repository. This title appears here courtesy of the author, who has retained all other copyrights. For more information, please contact thinkir@louisville.edu. 


\section{AN ANALYSIS OF TEACHER EFFICACY, RESIDENT EFFICACY, AND \\ TEACHER-STUDENT RELATIONSHIPS WITH BEHAVIORALLY CHALLENGED \\ YOUTH IN RESIDENTIAL TREATMENT SETTINGS}

By

Andrew J. Nichols

B.S., Utah Valley State University, 2002

M.C., University of Phoenix - Salt Lake City Campus, 2007

A Dissertation Submitted to

the Faculty of the Graduate School of the

University of Louisville

in Partial Fulfillment of

the Requirements for the Degree of

Doctor of Philosophy

College of Education and Human Development

Counseling Psychology

University of Louisville

Louisville, KY

August 2011 
Copyright 2010 by Andrew J. Nichols

All rights reserved 

AN ANALYSIS OF TEACHER EFFICACY, RESIDENT EFFICACY, AND

TEACHER-STUDENT RELATIONSHIPS WITH BEHAVIORALLY CHALLENGED

YOUTH IN RESIDENTIAL TREATMENT SETTINGS

By

Andrew J. Nichols

B.S., Utah Valley State University, 2002

M.C., University of Phoenix - Salt Lake City Campus, 2007

A Dissertation Approved on

May 28, 2010

by the following Dissertation Committee:

Dr. Kathy Rudasill

Dissertation Chair

Natalie Kosine

Sam Stringfield

Linda Shapiro

Dennis E. Wagner, Ed.D 


\section{DEDICATION}

This dissertation is dedicated to my son

Mr. Terren Makai Nichols

who always has, and always will,

inspire me to come from my highest place. 


\section{ACKNOWLEDGMENTS}

I want to thank my dissertation chair, Dr. Kathy Rudasill, for her tireless support and patience. She is the true role model of what a teacher should be. I also wish to thank each of my committee members: Dr. Sam Stringfield, Dr. Linda Shapiro, Dr. Natalie Kosine, and Dr. Dennis Wagner. I am fortunate in that I was able to work closely with each of you throughout my graduate career. I also wish to acknowledge Dr. Patrick Pössel for his willingness to chat about statistics when all other doors were closed.

This dissertation would never have been written without constant support and inspiration from friends throughout the country. Amy Gonshak's (a.k.a. The Fire) tireless energy to help young people is the single most important reason that this study was initiated; I am amazed by her passion and dedication to others. Dr. Nate Mitchell and Amanda Wyrick were the two best mentors a new doctoral student could have had, I would still be bumbling around the halls without them. I especially want to thank the Utah crew who never harassed me (too much at least) for all the powder and sun I was missing. A shout out is necessary to Dave Birkbeck, Cord Warr, Kurt Damschroder, Chip Tomsuden, Frank Vermatt, and Scott McLeod.

Finally, I want to send my deepest love to my fiancée Rebecca, my son Terren, and my parents Michelle and Doug. I would have no sense of efficacy were it were not for the blessings and lessons I have received from each of you. 


\begin{abstract}
AN ANALYSIS OF TEACHER EFFICACY, RESIDENT EFFICACY, AND

TEACHER-STUDENT RELATIONSHIPS WITH BEHAVIORALLY CHALLENGED

YOUTH IN RESIDENTIAL TREATMENT SETTINGS
\end{abstract}

Andrew J. Nichols

May 28, 2010

This dissertation contributes to the existing body of research investigating teacher efficacy, collective teacher efficacy, academic efficacy, and teacher-student relationships within residential treatment centers (RTCs) for adolescents. While past RTC research identifies a link between positive resident outcomes and supportive relationships with RTC staff members, no prior studies have investigated this link from the perspective of classroom teachers. Additionally, although specialized trainings strengthen interpersonal relationships between $\mathrm{RTC}$ residents and staff members, most are directed toward therapeutic and milieu staff, not teachers. The purpose of this study was threefold: (a) to examine whether teachers' individual and collective perceptions of teaching efficacy improved after a specialized training, (b) to identify whether students' perceptions of student-teacher relationship and academic efficacy improved after teachers received a specialized training, and (c) to examine whether individual and collective teacher efficacy has an association with student academic efficacy and the quality of the teacher-student relationship. 
One hundred seventy-four (boys $N=81$, girls $N=93$ ) adolescents enrolled at two different RTCs participated in this study. Several findings emerged: (a) separate trends in teacher efficacy appeared, teacher efficacy increased among teachers working with girls but decreased among those working with boys, (b) collective teacher efficacy among all teachers decreased after the training, (c) no differences in student academic efficacy occurred over time, (d) no differences in students' perceptions of the student-teacher relationship occurred over time, (e) students whose teachers had lower individual but higher collective efficacy scores had higher student-teacher relationship scores, and (f) student academic efficacy was not related to individual or collective teacher efficacy. This study showed that interactions between teachers and students in RTC settings are complex and multifaceted processes. Many results were inconsistent with prior studies, which have primarily examined students in non-RTC settings. This dissertation further emphasizes the need for continued research with students placed in RTCs. Implications for future research include the design of specialized trainings for RTC teachers, the enhancement of efficacy beliefs among RTC teachers and students, and the impact of gender and attachment traits (among both students and teachers) upon efficacy beliefs and teacher-student relationships. 


\section{TABLE OF CONTENTS}

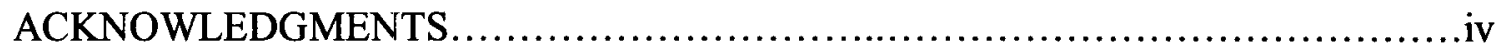

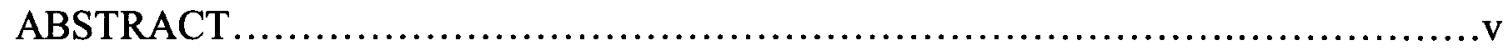

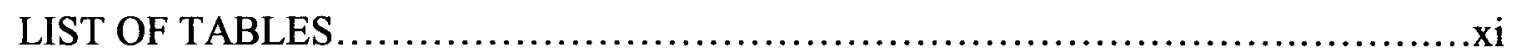

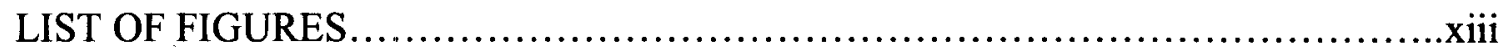

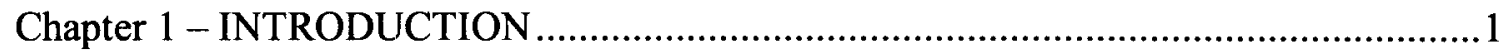

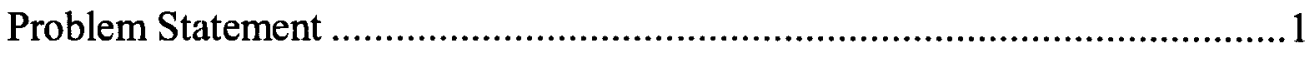

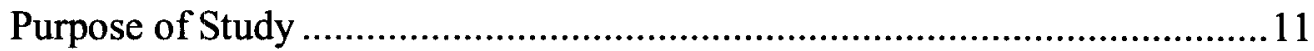

Research Questions ............................................................... 11

Chapter 2 - REVIEW OF THE LITERATURE............................................. 13

Adolescents in RTC Settings ..................................................... 13

Critical Areas of Intervention ......................................................... 14

Clinical Interventions .............................................................. 14

Milieu Interventions ............................................................ 16

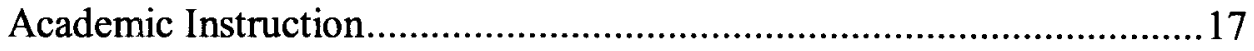

Introduction to Risking Connection ............................................. 18

Theoretical Frameworks of Study ....................................................20

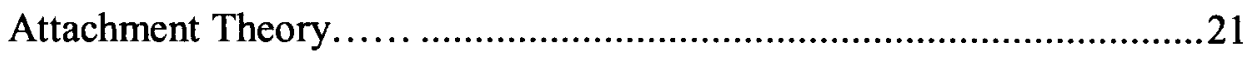

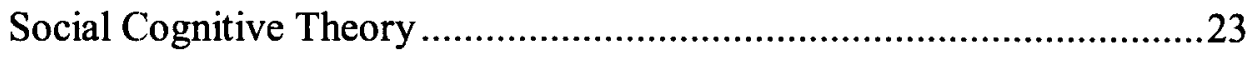

Pianta's Application of General Systems Theory to the Classroom ........26

Teacher-Student Relationship ..........................................................2

Teacher-Student Relationship and Academic Success ........................27 
Teacher-Student Relationship in Relation to Behavioral and Social

Development...

Student-Teacher Relationships and Attachment......................32

Gaps in the Teacher-Student Literature....................................................32

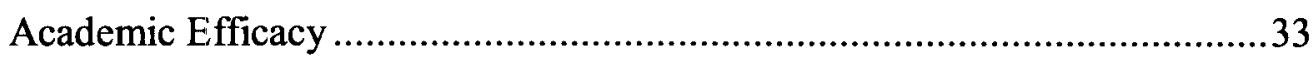

Academic Efficacy and Achievement ....................................................33

Generalizability of Academic Efficacy ...................................................35

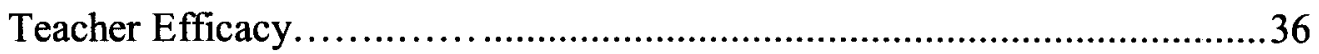

Teacher Efficacy and Academic Achievement ..................................37

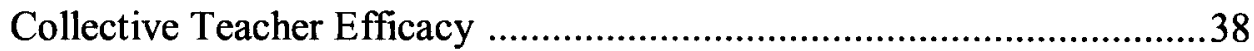

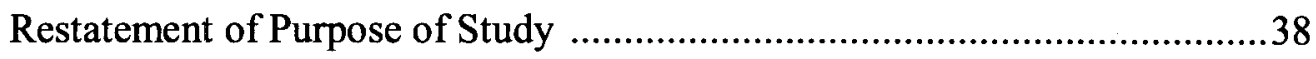

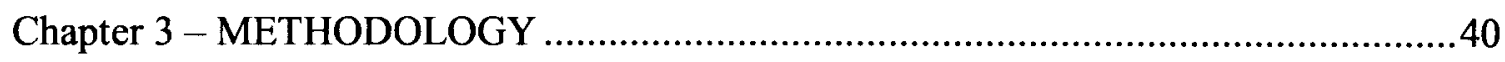

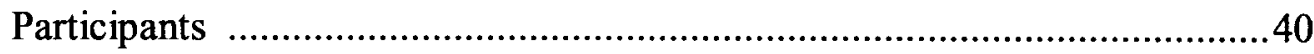

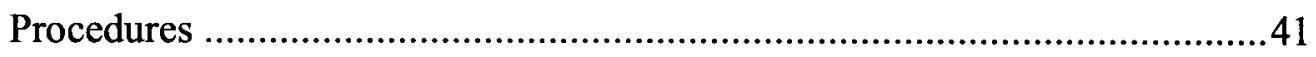

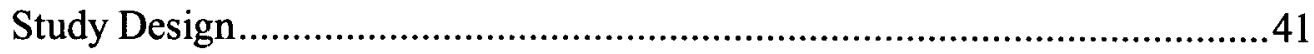

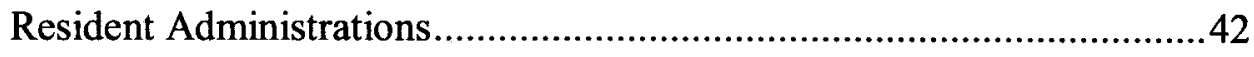

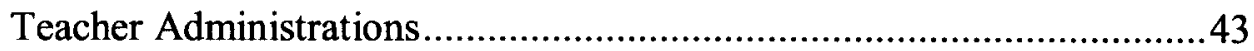

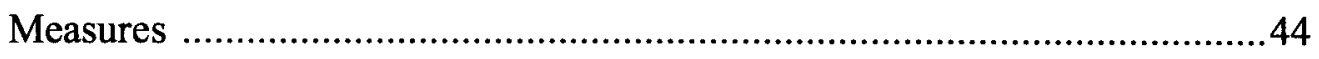

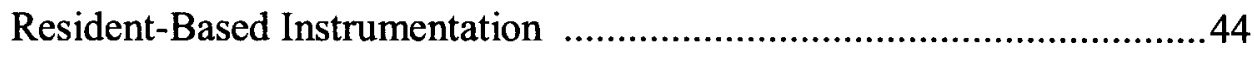

Your Relationship with this Teacher Scale .....................................4

Morgan Jinks Efficacy Scale .........................................................

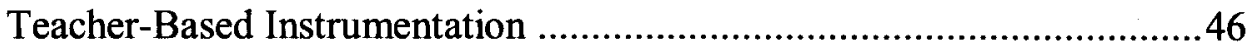

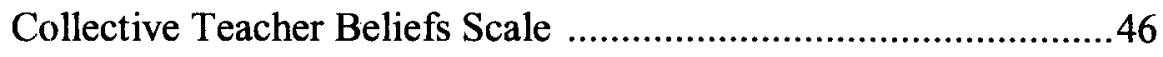




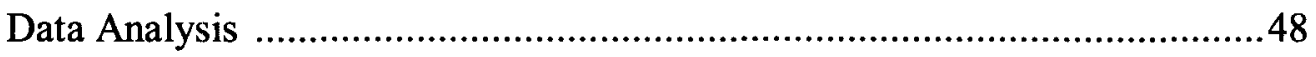

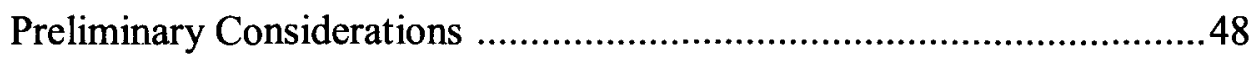

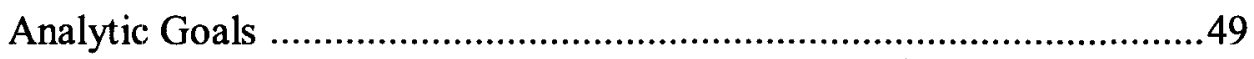

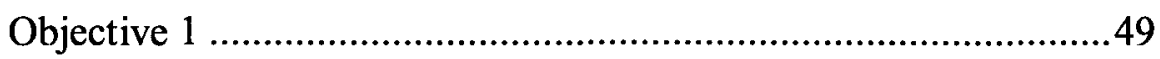

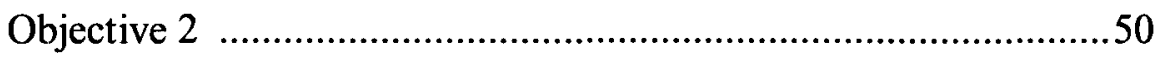

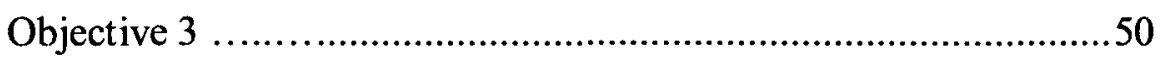

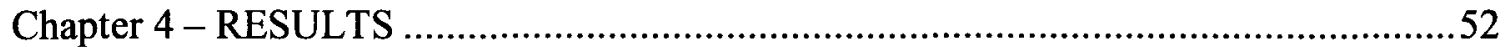

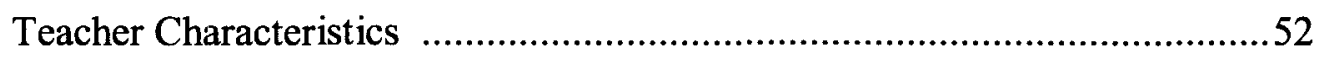

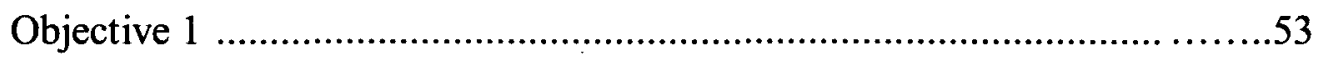

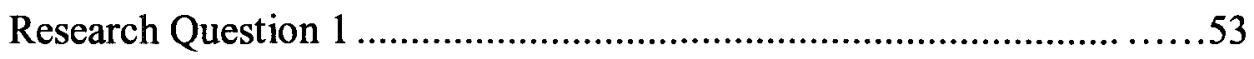

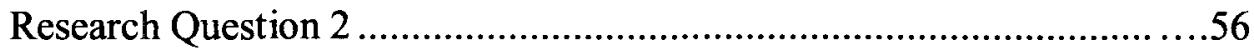

Student Characteristics................................................

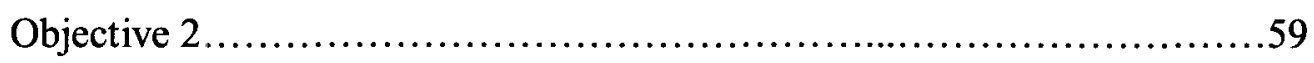

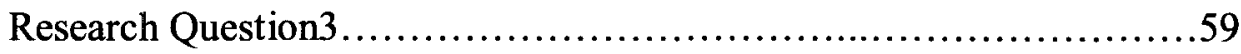

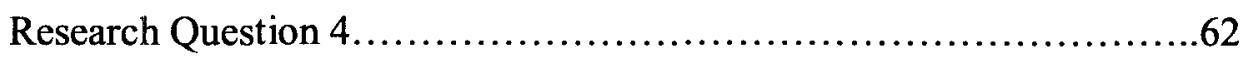

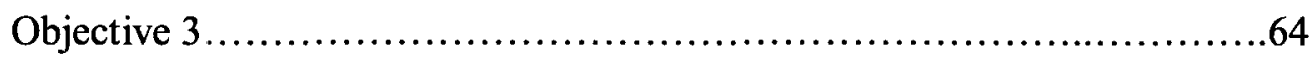

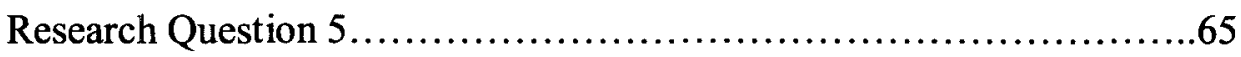

Research Question 6..........................................67

Chapter 5 - DISCUSSION AND CONCLUSIONS..............................70

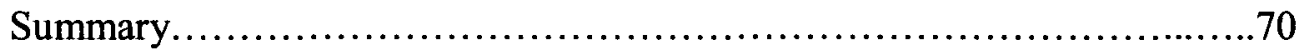

Discussion and Conclusions: Research Question 1 .....................72

Discussion and Conclusions: Research Question 2.....................74 
Discussion and Conclusions: Research Question 3........................76

Discussion and Conclusions: Research Question 4.......................77

Discussion and Conclusions: Research Question 5........................79

Discussion and Conclusions: Research Question 6.........................82

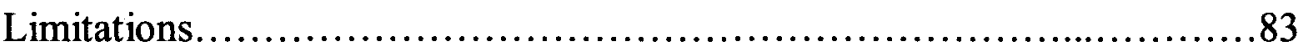

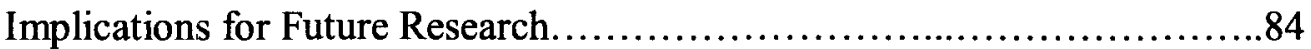

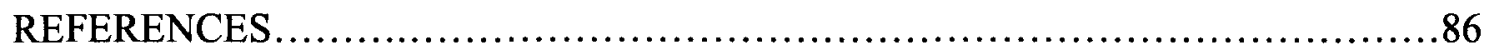

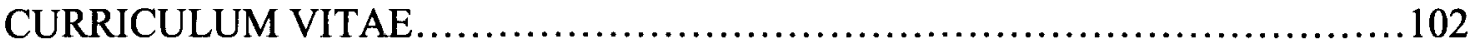




\section{LIST OF TABLES}

TABLE

PAGE

1. Means and Standard Deviations for the Teacher Sense of Efficacy Scale .54

2. Mixed-Model Analysis of Variance Results for the Teacher Sense of

Efficacy Scale. .54

3. Means and Standard Deviations for the Collective Teachers Beliefs Scale. .56

4. Mixed-Model Analysis of Variance Results for the

Collective Teachers Beliefs Scale. .57

5. Demographic Characteristics of Student Participants...........................58

6. Means and Standard Deviations for the Morgan-Jinks Student Efficacy Scale .60

7. Mixed-Model Analysis of Variance Results for the Morgan-Jinks

Student Efficacy Scale

8. Means and Standard Deviations for the Your Relationship with this

Teacher Scale

9. Mixed-Model ANOVA Results for the Your Relationship with this

Teacher Scale

10. Means, Standard Deviations, and Correlations for Your

Relationship with this Teacher Scale and Predictor Variables. 
11. Predicting Scores on Your Relationship with Teacher (RWT) Scale from Individual Teacher Efficacy, Collective Teacher Efficacy, and RTC Location.

12. Means, Standard Deviations, and Correlations for

Morgan-Jinks Academic Efficacy Subscales and Predictor Variables. .68

13. Predicting Scores on MJSES Subscales Talent, Context, and Effort from Individual and Collective Teacher Efficacy 69 


\section{LIST OF FIGURES}

FIGURE

PAGE

1. Diagram of Phase I: Student Pretest Administrations............................42

2. Diagram of Phase II: Student Posttest Administrations.........................43

3. Timeline of Teacher Pretest and Posttest......................................44

4. Trends in Teacher Efficacy Mean Scores from Pretest to Posttest....................55

5. Trends in Academic Efficacy Scores from Pretest to Posttest........................61, 76

6. Trends in Correlations between Teacher Efficacy Beliefs and Student

Perception of the Teacher-Student Relationship................................80 


\section{CHAPTER 1}

\section{INTRODUCTION}

\section{Problem Statement}

The purpose of residential treatment centers (RTCs) is to provide children and adolescents concentrated, multidisciplinary intervention for severe social, behavioral, and/or academic problems (Walter \& Petr, 2007). RTCs provide 24-hour, away-fromfamily care with most residents having previously failed in less restrictive environs such as a therapeutic day school or living with a foster family (Pierpont \& McGinty, 2004). From a definitional perspective the United States Department of Health and Human Services (2009) states that for an organization to be recognized as an RTC "the primary reason for the admission of 50 percent or more of the children and youth is mental illness that can be classified by DSMIV/ICD-9-CM codes other than codes for mental retardation, drug-related disorders, or alcoholism." While there are no specific criteria stating which behavioral problems are best served in the restrictive setting of a RTC, common issues faced by residents include poor impulse control, presence of antisocial and conduct disordered traits, neglectful or abusive familial relationships, and academic underachievement (McCurdy \& McIntyre, 2004; Whittaker, 2000).

The contextual settings for RTCs range from inpatient psychiatric facilities to communal group homes, but share the common feature of having residents who present with severe behavioral problems and who have been unsuccessful in one or more lessrestrictive settings (Foltz, 2004; Frensch \& Cameron, 2002; Walter \& Petr, 2007). An 
example of the high rate of prior placement for RTC residents was reported in a study by Baker and Curtis (2006) who found that only $11.3 \%$ of residents were admitted into an RTC as their first system of care with $47.6 \%$ of residents entering from the child welfare system, $28.9 \%$ from the psychiatric system, and $12.2 \%$ from the juvenile justice system. Baker and Curtis' results are troubling when examined from the perspective of best practices because most RTC residents have 'run out of options' in relation to finding less restrictive settings (Walter \& Petr, 2007). Such a lack of options is concerning because a common thread within the RTC literature repeatedly describes RTC placement as a highly invasive and disruptive process which should only be undertaken as a last resort (Bates, English, \& Kouidou-Giles, 1997; Frensch \& Cameron, 2002; Knorth, Harder, Zandberg, \& Kendrick, 2008). The concept of RTC placement being a disruptive last resort maintains that RTC placement supports feelings of inadequacy, incompetency, and brokenness on the part of residents as well as feelings of guilt and failure on the part of residents' families (Bates et al.; Frensch \& Cameron; Knorth et al.). Thus RTCs form an inherently challenging paradox where residents are too troubled to reside in a less structured environment, yet a resident's very presence in the RTC can further worsen the thoughts, feelings, and behaviors of residents and their family members.

One framework in which we can better examine the conflict between RTC placement and the risk of enhancing negative thoughts, feelings, and behaviors is attachment theory. Attachment theory is grounded in the concept that children who experience loss or deficits in care at a young age develop maladaptive thinking patterns or schemas (Bowlby, 1969). As a result, these negative schemas can contribute to significant emotional and behavioral problems later in life. Unlike object relations theory 
which presents maladaptive development as a result of unresolved frustrations at a developmental stage in the caregiver/child relationship (Hamilton, 1988), attachment theory focuses upon actual loss or traumatic events. Additionally, attachment theory examines childhood development as a continually evolving process rather than a sequence of stages requiring resolution before an individual can sufficiently develop healthy behaviors. This recognition allows for the impact of loss or trauma to be exacerbated or ameliorated by the absence or presence of positive attachment figures across a child's developmental process (Westen, Nakash, Thomas, \& Bradley, 2006). Attachment theory is especially valuable when examining intervention and outcome measures of RTC placement because it provides a platform for examining one of the few constants in RTC outcome research, the presence or absence of healthy relationships with family and RTC caregivers (Foltz, 2004; Frensch \& Cameron, 2002; Lyman \& Campbell, 1996; Walter \& Petr, 2007). Outcome studies through the nearly 40 years of RTC literature are routinely criticized as suffering from inadequate methodology, poor specificity in regard to treatment interventions, unclear definitions of what constitutes applied treatment, and difficulty with differentiating which aspect of RTC treatment has an impact on residents (Frensch \& Cameron, 2002; Lyman \& Campbell, 1996; Wells, 1991). As a result, one of the few clear indicators of short and long-term RTC success lies in the strength of attachments a resident maintains or repairs relationships with family members (both during and after treatment) and builds with RTC caregivers (Frensch \& Cameron, 2002).

Studies identifying the trend of positive attachments linking with post-RTC success have consistently appeared in the literature over the past several decades. Taylor 
and Alpert (1973) conducted one of the earliest outcome studies of RTCs and found few correlations between successful post-RTC adaptation (e.g. maintaining stable employment, not entering the adult criminal court system) and treatment interventions with the exception of perceived support from parents and RTC caregivers. Lewis (1982) produced similar results suggesting the only variable consistent with an adolescent's long-term success was parental involvement during and after RTC placement. Wells' (1991) examination of placement and follow-up variables related to RTC placement and outcome success revealed that high levels of positive engagement with peers, staff members, and academic tasks were correlated with successful follow up status. Finally, Knorth, Harder, Zandberg, and Kendrick (2007) examined 27 studies published from 1990 to 2005 via meta-analysis and found several key RTC outcomes: (a) positive behavior change (e.g. decreased number of outbursts in class) occurs more often among adolescents who present with externalizing rather than internalizing behavioral issues, (b) RTC staff are less likely to acknowledge resident progress than the residents and their families, (c) behavior modification and relationship-focused interventions are the most efficacious treatment modalities, and (d) specialized staff training, particularly in the cognitive and affective issues faced by RTC residents, can significantly strengthen the efficacy of RTC placement.

Examination of the concept that specialized staff training can contribute to the overall effectiveness of a resident's RTC experience is a central aspect of this study. There are very few training and intervention programs designed to specifically address the ability of direct care employees in RTCs to more effectively interact with their residents (Curry, 2004; Foltz, 2004; Walter \& Petr, 2007). This lack of training is 
particularly relevant to 'in-the-trenches' milieu and academic staff because their educational backgrounds do not typically emphasize the complex emotional and behavioral challenges the therapeutic staff have been trained to address (Walter \& Petr, 2007).

One of the few programs designed to provide specific training to caregivers in RTC settings, particularly those with populations exposed to trauma and neglect, is Risking Connection (Giller, Vermilyea, \& Steele, 2006). Risking Connection is a curriculum-based, two-day training intervention designed to provide direct care workers in RTC settings with a foundation of skills and increased awareness regarding issues of residents who have experienced childhood neglect, abuse, and trauma (Pearlman, 1998; Saakvitne, Tennen, \& Affleck, 1998). Risking Connection trains caregivers in two primary areas. First, Risking Connection helps caregivers understand that many victims of childhood abuse have been victims of chronic betrayal from adult caregivers; as a result, these individuals have developed sophisticated coping mechanisms which challenge adult caregivers via emotionally volatile and physically harmful behaviors. Second, Risking Connection encourages self-reflective thinking, which not only assists caregivers in interacting with residents, but also encourages caregivers to gain awareness and utilize their own emotional reactions in a productive manner (Giller, et al., 2006). Therefore, the focus of this study is to examine the effectiveness of the Risking Connection training for teachers in an RTC on positive outcomes for residents.

As previously noted, evidence suggests that post-RTC success appears to be related to the quality of relationships the resident has with family members, caregivers and RTC staff (Pierpont \& McGinty, 2004; Knorth et al., 2008). However, no research 
has been conducted in an RTC setting that examines the potential of specialized training to augment the teacher-resident relationship, nor do RTC-based studies exist which examine the use of specialized teacher training to enhance residents' academic and social skills (Walter \& Petr, 2007). The lack of research into the academic facet of RTC life is especially pertinent when results such as Libby et al.'s (2005) study of time spent within the classroom versus applied therapy are examined. In their study, Libby and colleagues examined over 40 RTCs in Colorado reporting that approximately $50 \%$ of an average resident's day is spent within the classroom environment while only $13 \%$ is spent within applied individual, group, or family therapy.

Since students in RTC settings spend $50 \%$ of their day in the classroom environment, variables such as teacher efficacy, teacher-resident relationships, and the wide-ranging benefits of residents' enhanced academic efficacy become key issues to examine. Teacher efficacy relates to a teacher's perception of her or his ability to influence the academic performance and social development of students within the classroom, especially with those students who are lacking in personal motivation or academic interest (Tschannen-Moran \& Hoy, 2001). Within the literature, there are numerous examples linking enhanced teacher efficacy to their higher goal setting, openness to pedagogical experimentation, and a willingness to explore alternate teaching methods (Stein \& Wang, 1988; Tschannen-Moran \& Hoy, 2001). For example, Allinder (1994) found that teachers high in efficacy tend to better maintain enthusiasm for their role as an instructor while demonstrating stronger and more consistent lesson planning and organizational skills. 
Research also suggests that teachers with high levels of efficacy interact in a more diligent and supportive manner with their students. High levels of teacher efficacy have been linked to improvements in teachers' ability to remain committed in working with challenging students or situations (de la Torre Cruz \& Casanova Arias, 2007), a stronger degree of support and patience with students who are struggling (Gibson \& Dembo, 1984; de la Torre Cruz \& Casanova Arias), and lower likelihood of referring challenging students to special education interventions outside of their classroom (Soodak \& Podell, 1993). Additionally, the construct of teacher efficacy has been positively associated with student outcomes via enhanced academic achievement and motivation (Goddard, Hoy, \& Hoy, 2004; Jinks \& Morgan, 1999; Midgley, Feldlaufer, \& Eccles, 1989; Ross, 1992; Tschannen-Moran \& Barr, 2004), increased levels of academic efficacy (Anderson, Greene, \& Loewen, 1988), and the maintenance of positive classroom environments (Tschannen-Moran \& Hoy, 2001). Finally, teacher efficacy has been found to be predictive of positive and negative dynamics within the teacher-student relationship. For example, in one study of low achieving students Yeo et al. (2008) found teacher-student relationships high in conflict predicted low ratings in teacher efficacy.

It is important to note that while the relationship between teacher efficacy and positive teacher/student outcomes is well documented within the literature, research involving teacher efficacy, academic success, and other related outcomes of students in RTC settings is quite sparse. Only one article has been published to date on teacher efficacy and at-risk student populations (see Alderman, 1990), with no specific studies specifically addressing RTC settings. 
The role of teacher-student relationships provides another unique perspective to investigate residents' RTC experience. There is a fairly substantial body of evidence suggesting that a positive teacher-student relationship can contribute to the reduction of negative and disruptive behavior in the classroom while enhancing academic motivation and success (Abbott \& O'Donnell, 1998; Greenberg et al., 2003; Pianta, 1999; RimmKaufman \& Chiu, 2007). For example, Wentzel (1998) demonstrated that teacher support was negatively correlated with emotional distress, and in a later work (2002), found that teachers are more likely to impact student's classroom motivation and behavior than their parents. Herrero, Estévez, and Musitu (2006) found similar results reporting a negative correlation between healthy teacher-student relationships and deviant behavior and psychological distress on the part of students. Additionally, strong teacher-student relationships have been linked to reducing negative behaviors such as harmful sexual behavior (Voisin et al., 2006) and aggression (Cavell, Elledge, Malcolm, \& Faith, 2009; Meehan, Hughes, \& Campbell, 2003). Finally, researchers such as Klem and Connell (2004) and Goodenow (1993) investigated classroom belonging in relation to achievement and motivation, with both finding that students' perceived levels of teacher support are more influential than their own intrinsic values in student effort and academic success.

A challenge faced when attempting to generalize findings relating to positive teacher-student outcomes is that the majority of associated studies have used convenience samples within conventional classrooms rather than applied examination in an RTC setting. As a result, there are very few studies which specifically examine teacher-student relationships within the auspices of the RTC environment and those that do (see Lane, 
Barton-Arwood, Nelson, \& Wehby, 2008) tend to accentuate behavioral issues rather than academic and interpersonal outcomes (Lane et al.). This deficit is exemplified in Reid et al.'s (2004) meta-analysis of academic status among students with emotional/behavioral disturbances (EBDs). Reid examined 25 different studies related to EBDs and found that only one was conducted in an RTC setting. Comparable examples of studies examining teacher-student dynamics with populations similar to an RTC include Voisin et al.'s (2005) study of teacher connectedness and its relationship to gang membership, substance abuse, and risky sexual behavior in a juvenile detention center, and Lane et al.'s examination of academic, social, and behavioral performance among EBD students in a self-contained school setting.

A third perspective relative to the significant amount of time RTC residents spend in the classroom examines the relationship between improvements in teacher efficacy and improvements in residents' academic efficacy. Academic efficacy is a measure of a student's perceived ability to successfully complete academic tasks and stems from generalized self-efficacy, a product of Bandura's social cognitive theory (Bandura, 1986; Zimmerman, Bandura, \& Martinez-Pons, 1992). Social cognitive theory posits that as we experience successes and failures in life, we construct general beliefs regarding our ability to succeed or fail in similar future endeavors. Areas related to efficacious learning behavior include choosing to engage in creative problem solving, seeking teacher assistance, motivation, academic perseverance, and high achievement (Jinks \& Morgan, 1999). As a result, students with high levels of academic efficacy are much more likely to be self-directed learners, actively set challenging academic goals, and apply creative learning strategies to attain their goals (Bandura, 1989; Bandura \& Cervone, 1983; 
Zimmerman, 1990). Additionally, students high in academic efficacy are more persistent, tackle academic challenges with more effort, and show more interest in school than their peers who present with low levels of academic efficacy (Schunk, 1984; Schunk, 2001). The end result is that students who expect to succeed academically do in fact succeed, while those who expect to fail tend to fail (Bandura, 1986; Margolis \& McCabe, 2004).

The concept that students expecting academic success or failure tend to manifest such results is critical in developing interventions which bolster academic efficacy along two lines. First, research indicates that teacher efficacy can enhance student academic efficacy (Anderson et al., 1988; Margolis \& McCabe, 2004,). Teachers with high levels of teaching efficacy are more likely to strengthen a student's perception of academic efficacy by virtue of proactively teaching new strategies, helping to set and attain realistic short-term goals, and reinforcing recent successes (Ormond, 2000; Pajares \& Schunk, 2001). Second, while some researchers contend that measurement of self-efficacy is taskspecific (Finney and Schraw, 2003), others suggest that, in line with the precepts of social cognitive theory, a relationship between various broad and specific dimensions of efficacy allows for an expanded view of the nature and structure of generalized selfefficacy (Choi, 2005). Along these lines a growing body of research suggests that a degree of generalizability exists within the construct of academic efficacy with broader aspects of an individual's sense of overall self-efficacy (Bong, 1997). Thus, the concept of generalizability among various constructs of self-efficacy appears to have the potential to bolster academic efficacy from one subject to another and to enhance similar but 
uniquely different constructs such as self-worth, self-perception, and self-esteem (Bong, 1996; Bong \& Skaalvik, 2003).

\section{Purpose of Study}

No prior study has examined the domains of teacher efficacy, collective teacher efficacy, resident academic efficacy, and resident perception of the teacher-student relationship in an RTC setting. As a result, the purpose of this study is threefold: (a) to examine whether teachers' individual and collective perceptions of teaching efficacy improve after receiving the Risking Connection training, (b) to identify whether residents develop marked improvements in perceived strength of teacher-student relationship and academic efficacy after their teachers receive the Risking Connection training, and (c) to examine - prior to teachers receiving the Risking Connection training - whether teacher efficacy has a positive or negative association with student efficacy and the quality of the teacher-student relationship.

Research Question 1: Will the Risking Connection training enhance teacher efficacy in an RTC setting?

Research Question 2: Will the Risking Connection training increase teacher perception of collective teacher efficacy in an RTC setting?

Research Question 3: After having their teachers receive the Risking Connection training, will students' perceptions of academic efficacy increase?

Research Question 4: After having their teachers receive the Risking Connection training, will students' perceptions of their teacher-student relationship improve? 
Research Question 5: To what degree is individual and collective teacher efficacy associated with levels of student perception regarding the quality of their teacher/student relationship?

Research Question 6: To what degree is individual and collective teacher efficacy associated with levels of student academic efficacy? 


\section{CHAPTER 2}

\section{REVIEW OF THE LITERATURE}

\section{Adolescents in RTC Settings}

Residential Treatment Centers (RTCs) provide children and adolescents concentrated, multidisciplinary interventions which address severe social, behavioral, and academic issues. As RTCs grow into their fourth decade of existence, the challenges residents and staff members face continue to become more complex (Foltz, 2004; Walter \& Petr 2007). These challenges are highlighted by the fact that most RTC residents are diagnosed with serious behavioral disorders (SBDs) such as attention deficit, conduct, and affective disorders (e.g. anxiety and depression). As a result residents tend to present with chaotic behavior, weak impulse control (e.g. threatening others or destroying walls and doors), suicidal ideations/attempts, and sexually acting out. Prior to placement, many residents may also have struggled with abusing alcohol and illegal substances. Additionally, most residents have experienced strained familial relationships, profound feelings of rejection, and several foster care settings (Foltz; Knorth et al., 2008; Walter \& Petr).

Even as the demand for empirically supported interventions grows throughout the mental health field, there remains a relative absence of outcome-based literature and clear definitions of what an RTC is and who should be placed there. Residents presenting with more complex diagnoses, including dual-diagnoses, create an incredibly challenging environment for RTC caregivers (Curry, 2004; Foltz, 2004; Knorth et al., 2007). 
Contributing to this dilemma are the complex inter-relationships within the various departments, employees, and training or professional backgrounds of staff members who work within an RTC (Connor et al., 2003; Walter \& Petr, 2007). RTC settings are typically comprised of social workers, therapists, milieu staff, recreational staff, kitchen staff, academic teachers, and administrative support staff (Foltz, 2004; Walter \& Petr, 2007). With such a diverse array of professionals (with equally broad educational backgrounds) interacting with residents, consistency in treatment approach and course of care is difficult to maintain (Foltz, 2004).

\section{Critical Areas of Intervention}

Surveys of RTC programs have informed us that a relatively similar set of services is provided throughout most programs (Libby et al., 2005; Whittaker, 2000). Within most RTC settings the multidisciplinary focus tends to center upon three distinct branches: clinical/therapeutic care, milieu care, and academic classroom interventions.

\section{Clinical Interventions}

The first branch focuses upon clinical treatment and is typically compromised of a blend of social workers, mental health counselors, nurses, psychiatrists, and occasionally psychologists (Foltz, 2004; Frensch \& Cameron, 2002). Given that approximately $13 \%$ of a resident's day is spent in direct clinical contact (via individual, group, and family therapy) it is interesting that this is the arena of RTC care that has received the most investigation within the literature (Libby et al., 2005; McGurdy \& McIntyre, 2004). Such a focus likely occurs due to the clinical nature of RTC programming and the significant danger to self and others residents present upon admission (McGurdy \& McIntyre, 2004). One element likely contributing to this imbalance within the literature lies with the fact 
that most $(76 \%)$ residents in an RTC setting have been prescribed psychotropic medication with $40 \%$ of residents receiving two or more psychotropic interventions (Connor \& McLaughlin, 2005).

The primary treatment modalities within RTCs are described as cognitivebehavioral and eclectic, with a relatively small percentage (approximately $9 \%$ ) adhering to psychodynamic, psycho-educational, object-relations, or systems theories (Foltz, 2004). With such a high adherence to process-based therapy, strong verbal and cognitive skills would appear to be a prerequisite for clinical success in RTC environs. However, what literature that does exist on this concept suggests that many RTC residents are lacking in these very skills (Edwards \& Chard, 2000; McMackin, Tansi, \& Hartwell, 2005).

This is especially striking when considering results such as McMackin, Tansi, and Hartwell's (2005) study of basic educational skills in relation to juvenile offenders in an RTC setting. McMackin and colleagues examined outcome variables (program graduation and attempted escapes) between residents presenting with $9^{\text {th }}$ grade reading comprehension and vocabulary skills versus those achieving at a $6^{\text {th }}$ grade level. In both instances, residents at a ninth grade level were more likely to complete the program and not attempt to escape (the juvenile setting) as compared to their lower achieving peers. Another challenge faced by the clinical branch lies with the fact that most outcome studies suggest that familial support and the development of healthy relationships with alternative adult caregivers are the most likely predictors of post-RTC success (Foltz, 2004; Frensch \& Cameron, 2002; Lyman \& Campbell, 1996; Walter \& Petr, 2007). These results are in stark contrast with studies suggesting that the majority of an RTC 
resident's clinical time is spent in group and milieu therapy with only about one hour directed toward family therapy (Libby et al., 2005, Walter \& Petr). These challenges suggest that while clinical care and safety are fundamental priorities of RTCs, training specific to residents' backgrounds and issues - especially with those employees traditionally perceived as being non-therapeutic - could enhance the experience of RTC residents (Giller, Vermilyea, \& Steele, 2006; Knorth et al., 2008).

\section{Milieu Interventions}

The second branch of RTC emphasis focuses upon direct care or milieu staff members (sometimes referred to as residential staff, dorm staff, mental health technician, etc.; for brevity they will be referred to as milieu staff throughout this paper). These direct care employees are responsible for directing and managing residents throughout their day, providing supervision between classes and at meals, assisting with homework, and maintaining safety and discipline within the living environs (Walter \& Petr, 2007). Beyond the classroom environment, it is under the auspices of the milieu staff that RTC residents spend a significant portion of their time (Libby et al., 2005). Milieu staff are critical components of RTC care because they tend to be the primary implementers of interventions and assignments prescribed by clinical and academic staff (Libby et al.; Walter \& Petr). Additionally, by virtue of the significant amount of time spent together, milieu staff are capable of developing strong and beneficial relationships with RTC residents. For example, on a given day milieu staff are expected to engage and hold residents accountable for room cleanliness and shared chores, escort residents to classes, supervise residents at meals, implement interventions such as token economies and social skills training, assist residents with schoolwork, and contribute to therapeutic groups 
(Comaty et al., 2001; Conner et al., 2003; Mathur, Kavale, Quinn, Forness, \& Rutherford, 1998; McCurdy \& McIntyre, 2004).

Given the incredible amount of responsibility, emotional and physical safety concerns, and direct-care intervention asked of milieu staff it is not a surprise that they (along with academic teachers) represent the highest degree of employee turnover within RTC settings (Connor et al., 2001; Walter \& Petr, 2007). For example, Connor et al. reported a $46.1 \%$ turnover rate for milieu staff within a 3.5 year observation period in their study. Such turnover rates could be especially harmful to residents as many suffer from attachment issues, poor consistency in the presence of adult role models, and histories of neglect. Such challenges again suggest that training specific to RTC residents' backgrounds and issues - especially with those employees traditionally perceived as being non-therapeutic - could enhance the experience and chances for postRTC success (Giller, Vermilyea, \& Steele, 2006; Knorth et al.).

\section{Academic Instruction}

The third branch of RTC care lies within the classroom day and residents' interactions with academic teachers (Frensch \& Cameron, 2002). As was stated in chapter one, approximately $50 \%$ of an RTC resident's day falls under the auspices of academic instructors in comparison to approximately $35 \%$ of the day with milieu staff, and around $13 \%$ of the day with clinical care staff (Libby et al., 2005). Academic teachers play a critical but under-studied role within RTC settings due to their dual responsibilities to students. First, teachers in RTC settings have a responsibility to engage the most troubling of students in fundamental academic skills which are critical for successful completion of an RTC placement and successful post-RTC life (Lane et al., 2008; 
McMackin, Tansi, \& Hartwell, 2005; U.S. Department of Education, 2009). However many RTC teachers receive little training regarding how to best interact with these students in their classrooms (Coleman \& Vaughn, 2000; Edwards \& Chard, 2000). Second, there is a wealth of research documenting the critical role of positive teacherstudent relationships for students' successful outcomes, especially for those students identified as high-risk (Decker, Dona, \& Christenson, 2007; Klem \& Connell, 2004; Meehan, Hughes, \& Cavell, 2003).

Positive teacher-student relationships can provide a groundwork which increases academic performance and enhances positive outcomes later in life. This seems particularly pertinent to children in RTC settings due to the learning problems inherent in most residents. While approximately $10 \%$ of adolescents within the broad population present with some sort of academic limitation, approximately $70 \%$ of delinquent students present with some sort of learning difficulty or deficiency (Leone, Zaremba, Chapin, \& Iseli, 1995). Additionally EBD students have more academic deficits and learning issues than their peers (McEvoy \& Welker, 2000) and typically fall behind academically in elementary school with their deficits becoming more marked as they move into secondary school (Epstein, Kinder, \& Bursuck, 1989). As a result, over 50\% of EBD students never complete high school (U.S. Department of Education, 2009). For these reasons, it is critical that we understand more about teachers in RTC settings.

\section{Introduction to Risking Connection}

There are very few training and intervention programs designed to specifically augment the ability of direct care providers in RTC settings to successfully interact with their residents (Curry, 2004; Foltz, 2004; Walter \& Petr, 2007). Such a lack of specific 
training is especially pertinent to teachers who work with these students at-risk for academic difficulty or with EBDs. For example, Reid et al.'s (2004) meta-analysis of 26 studies examining the academic performance of students presenting with EBDs produced an overall effect size of -.64. These data demonstrated a strong negative relationship between students with EBDs and academic measures such as reading, vocabulary, arithmetic, and written expression. Such results are compounded by studies suggesting that academic achievement can be enhanced by positive teacher-student relationships (Cavell, Elledge, Malcolm, Faith, \& Hughes, 2009; Croninger \& Lee, 2001; Decker, Dona, \& Christenson, 2007) Such relationships, in turn, can have a direct link between the development and maintenance of pro-social behaviors, feelings of self-worth, and mediate deviant behavior (Decker, Dona, \& Christenson; Meehan, Hughes, \& Cavell, 2003; Resnick \& Bearman, 1997; Rimm-Kaufman \& Chiu, 2007).

One program designed to provide specific training to caregivers in RTC settings, particularly those with populations exposed to trauma and neglect, is Risking Connection. Risking Connection ( $\mathrm{RC}$ ) is a curriculum-based training program created to provide mental health and human service professionals with a philosophy and method for working with clients who are survivors of childhood abuse and trauma. RC is grounded in constructivist self development theory (CSDT) which describes the impact of traumatic life events on the development of the individual. CSDT is closely aligned with the theoretical frameworks of this study by recognizing that individuals construct meaning from life traumas based upon environmental factors, self-perceptions, and secure or insecure attachments (Pearlman, 1998; Saakvitne, Tennen, \& Affleck, 1998). 
$\mathrm{RC}$ assists a diverse range of caregivers within a clinical setting (e.g. therapists, milieu staff, and academic faculty) by providing a shared foundation of interpretation and intervention. Training is focused on encouraging understanding that many victims of childhood abuse have been victims of chronic betrayal from adult caregivers. These children have developed sophisticated coping mechanisms which push away adult caregivers via emotionally and physically harmful behaviors. As a result, $\mathrm{RC}$ emphasizes healing through encouraging children to "risk" re-developing relationships without the utilization of negative behaviors.

A secondary benefit of RC lies in its self-reflective training, which not only assists caregivers in interacting with residents, but also encourages caregivers to gain awareness and utilize their own emotional reactions in a productive manner. Thus by gaining awareness of caregivers' individual reactions brought on by interacting with residents, caregivers can learn to focus their emotions in a manner reinforcing empowerment, partnership, and trust (Giller, Vermilyea, \& Steele, 2006). In this manner of respecting and enhancing the two-dimensional relationship in the caregiver-resident relationship, $\mathrm{RC}$ also shares a theoretical value with Pianta's utilization of general systems theory within the classroom environment. As a result, while implementation of the RC program is not the focus of this study, the shared commonalities between RC and the theoretical frameworks presented below provide an excellent foundation to explore the research questions driving this study.

\section{Theoretical Frameworks of the Study}

This study is grounded in three theoretical models. These are attachment theory (Bowlby, 1968; Ainsworth, Blehar, Waters, \& Wall, 1978; Maine \& Solomon, 1986), 
social cognitive theory (Bandura, 1986; Zimmerman, Bandura, \& Martinez-Pons, 1992), and Pianta's application of general systems theory (GST) to the classroom (Pianta, 1999).

\section{Attachment Theory}

According to attachment theory early childhood attachments directly contribute to schema and metacognitive development (Westen et al., 2006). Bowlby suggested that cognitive thoughts and affective behaviors develop via positive and negative interactions with attachment figures critical to the child and at a relatively early stage in their cognitive development (Bowlby, 1968). According to attachment theory the impact of these interactions directly influences a young child's internal working model (IWM) which drives a developing child to develop positive or negative thinking patterns in relation to her or his own self-worth and the reliability of caregiver's ability to provide attention and care.

Empirical measurement of attachment theory - and evidence that a child's cognitive ability to process information begins at a young age - was examined in 1978 within Ainsworth, Blehar, Waters, and Wall's "Strange Situation" experiment. By removing a child's primary caretaker (while placing a stranger in the room for the interim), Ainsworth was able to outline three discrete reactions on the part of infants upon their caretaker's return: (a) secure - whereby children responded to the caretaker's return with signs of enthusiasm and comfort, (b) anxious/avoidant - whereby the child appeared disinterested with their caregiver's return, and (c) anxious/ambivalent (ambivalent is now usually substituted with the phrase 'resistant') - in which case the child initiated contact with the caregiver but the contact failed to have a calming effect. During proceeding attempts to replicate Ainsworth et al.'s research, Main and Solomon 
(1986) noticed a tendency for some children to not accurately fit within Ainsworth's three categories of attachment type-ultimately defining a fourth characteristic of childhood attachment issues as disorganized — whereby the child presents with incoherent response patterns to separation and reunion, contradictory behavior patterns, and disorientation.

The aforementioned attachment types are well documented within the literature to have specific emotional and cognitive behavior patterns. Children who are victims of sexual abuse, neglect, high-risk home environments, and poverty are all at significant risk of developing insecure (e.g. avoidant, ambivalent, and disorganized) attachments (Kennedy \& Kennedy, 2004; Main \& Solomon, 1990). Disturbing prevalence rates within the literature support this concept. Lyons-Ruth, Esterbrooks, and Cibelli (1997) studied disruptive behavior in young children finding $87 \%$ of children in their study presented with disorganized attachment (leading to externalizing behaviors, ADHD, and conduct issues). Greenberg, Speltz, DeKlyen, and Endivia (1991) examined children referred to treatment, and found $82 \%$ of their subjects presented as some type of insecure attachment with $40 \%$ exhibiting a disorganized attachment pattern. Finally, van IJzendoorn, Schuengel, and Bakermans-Kranenburg (1999) performed a meta-analysis of attachment in maltreated children and posited that disorganized attachment tendencies among maltreated children could be as high as $77 \%$.

The abovementioned attachment patterns have the potential to be highly relevant to academic instructors in an RTC setting (Kennedy \& Kennedy, 2004). It is possible that caregivers and school teachers can develop healthy attachments with RTC residents by providing physical and emotional care, being reliably present in a young person's life, 
and having a consistent emotional investment with the individual (Howes, 1999). As a result, teachers have the potential to fulfill the role of a primary attachment figure and enhance the development of positive thinking patterns within a student's internal working model (Pianta \& Steinberg, 1992; Kennedy and Kennedy, 2004). Bowlby (1969) expressed that learning is best achieved within an environment that fosters exploration and provides a safe attachment foundation. Thus the teacher-student relationship has the potential to evolve as an interactive and vibrant bond which can evolve over the course of the student-teacher relationship (Pianta, 1999).

One final aspect of attachment theory that is pertinent to academic instructors in RTC settings lies in an individual teachers' ability to self-reflect upon his or her own attachment styles. Just as understanding the internal working model of students can be beneficial in better understanding the origins of their maladaptive behaviors, teachers must recognize that the externalized behavior of their students can be a reflection of their own negative emotions in the classroom (Kennedy \& Kennedy, 2004). For example, Bergin and Bergin (2009) found that in the classroom teachers with insecure attachments are more likely to have negative perceptions of insecure students. Moreover Al-Yagon and Mikulincer (2004) found that teachers working closely with learning disordered children in conventional classrooms experienced lower levels of emotional closeness with these students when compared to typically developing children.

\section{Social Cognitive Theory}

Social cognitive theory is a theory of learning conceived on the precept that children gain knowledge by vicariously observing the actions of others and therefore developing independent cognitions affecting their ability to function and adapt within 
their environment (Bandura, 1986, 1989). As a result learning occurs by process of an active integration between a child's environment, behaviors she or he witnesses within the environment, and cognitions the child develops as she or he interacts with others. For instance, actions of others can alter a child's cognitions, while simultaneously the environment the child lives in can interlace with these cognitions to impact the child's behavior. Additionally, the mindset of a child's caregivers can determine the environment in which a child is raised. The end result is that cognitions, behaviors, and environment are constantly intertwining to impact a child's cognitive development.

Bandura is the most common theorist associated with social cognitive theory by virtue of his elaboration of the theory's fundamental concepts in regards to personality development and self-efficacy (Bong, 1997). Within this context, self-efficacy is operationally defined as an individual's perception of his or her ability to control and manifest the outcomes and experiences that impact his or her life (Bandura, 1989). As a result, Bandura elaborated upon social cognitive theory via four key concepts: mastery experiences, vicarious learning, verbal influence, and affective/physiological states (Bandura, 1986).

Mastery experiences are the primary facet of Bandura's concept of self-efficacy. Mastery experiences are events of success and familiar in multiple scenarios which impact developing cognitive function. If early success is easily attained then future failure can contribute to high levels of discouragement. If failures repeatedly occur prior to the attainment of self-efficacy, then self-efficacy development can be impaired. And finally, if accomplishment occurs after a child experiences struggle then a sense of resiliency is developed (Bandura, 1986, 1989, 1997). Secondly, vicarious learning (or 
modeling) contributes to the development of positive or negative efficacy by virtue of developing a sense of personal capability in relation to the behavioral outcomes of significant others. For example, the success or failure modeled by caregivers directly influences conclusions that the child learns to expect as standard outcomes within their own life. The third concept of verbal influence recognizes the role of positive or negative feedback a child receives from caregivers. As a result, when positive feedback occurs, a healthy sense of efficacy is engendered, yet when negative verbal reinforcement occurs feelings of inadequacy and incompetence are reinforced (Bandura, 1986, 1989, 1997). Finally, Bandura recognized the importance of physiological and affective states in a child's ability to develop positive self-efficacy. Therefore feelings of anxiety and stress contribute to poor development of efficacious beliefs while emotions centered upon calmness and safety enhance a child's expectancy of success and positive outcomes (Bandura, 1986).

One final, but critical, component of self-efficacy is the concept of outcome expectations (Jinks \& Morgan, 1999). Even with individuals who report high levels of self-efficacy, completion of tasks or goals will not occur without a sound foundation of knowledge and skills about the activity an individual is attempting to undertake. For example, an individual could have a strong sense of efficacy regarding the ability to earn an ' $A$ ' in an advanced statistics course. But if that individual has not successfully undertaken and completed the necessary prerequisite coursework, she or he could not possibly be placed into such an advanced statistics course and expect to succeed.

Outcome expectations are critical to developing and maintaining self-efficacy because an individual will not attempt tasks they do not believe will lead to a successful conclusion. 
Consequently, positive outcome expectations maintain the development of self-efficacy and serve to drive motivation via increased effort, perseverance, and attainment of goals (Bandura, 1986; Pajares \& Schunk, 2001).

\section{Pianta's Application of General Systems Theory to the Classroom}

The final theoretical precept which contributes to this study is Pianta's application of general systems theory (GST) to the classroom environment (Pianta, 2001). GST grew out of ethological science as an argument in contrast to the scientific method (Spronck \& Compernolle, 1997). Briefly, scientific method proposes that complex systems can be examined by virtue of extricating them into individual components, examining each component separately, and then evaluating them in a linear manner to better understand the function of the system. By contrast, GST posits that systems are better viewed from a holistic perspective with the sum of an organism's perceptions, thoughts, and experiences being more valuable than its singular parts (von Bertalanffy, 1975).

Pianta's contribution lies in the application of GST within the experiences children have in academic settings (Pianta, 1999, 2001, 2006) and is linked to two primary facets. First, the teacher-student relationship has the potential to be incredibly influential in a child's development. In this regard Pianta's application of GST shares many parallels with attachment theory (see Crittenden \& Dallos, 2009; Erdman \& Caffery, 2000; Kennedy \& Kennedy, 2004), emphasizing a teacher's ability to provide physical and emotional care, maintain a reliable presence in a young person's life, present positive modeling of behavioral and academic tasks, and provide consistent emotional care to a child (Howes, 1999; Pianta, 1999; Rimm-Kaufman \& Chiu, 2007). Secondly, teachers have the ability to regulate a child's learning and social interactions within the 
context of the holistic classroom community (Rimm-Kaufman \& Chiu). Well trained teachers can provide social structure to the classroom environment via expectations and teaching styles. Also, teachers foster strong relationships within their students and between peers while devising behavioral interventions which engender positive student behavior within the classroom setting (Pianta, 1999, 2006; Rimm-Kaufman \& Chiu, 2007).

\section{Teacher-Student Relationship}

A prevalent theme in the teacher-student relationship literature is that positive student-teacher interactions are the single most critical factor for a student's healthy adaption to school (Kennedy \& Kennedy, 2004; Pianta, 1992), positive academic interest and achievement (Klem \& Connel, 2004; Wentzel, 1998), and classroom motivation (Goodenow, 1993; Hamman, \& Hendricks, 2005). At the same time, the student-teacher relationship has consistently been found to be a critical mediator in students' deviant behavior, psychological distress, and dropping out (Croninger \& Lee, 2001; DiLalla, Marcus, \& Wright-Phillips, 2004; Herrero, Estevaz, \& Musitu, 2006; Meehan, Hughes, \& Cavell, 2003). Such findings are especially pertinent to the RTC setting because students who are categorized as at-risk (e.g. students who are victims of sexual abuse, neglect, high-risk home environments, poverty, and have had past academic difficulties) are more likely to receive positive social and academic outcomes as a result of encouraging teacher-student relationships (Croninger \& Lee; DiLalla et al.; Meehan et al.).

Teacher-Student Relationship and Academic Success

Teacher-student relationships have been associated with a student's academic success, especially among children who are defined as at-risk (Klem \& Connell, 2004). 
Resnick and Bearman (1997) suggested that in healthy teacher-student relationships, teachers provide extra attention to students, and this relationship can serve as a mediator to certain risk-factors (e.g. insecure attachments, low academic efficacy, poor modeling of behaviors consistent with academic success from outside caregivers). Hamre and Pianta (2001) found similar results in their examination of the quality of teacher-student relationships. Their findings suggested that stronger teacher-student relationships were related to more teacher effort and attention toward providing resources to enhance students' success. Additionally, Hamre and Pianta reported that poor teacher-student relationships were more likely to create tension for students which could be linked to declines in achievement and classroom motivation. As a final example, in Goodenow's (1993) examination of perceptions of belonging among early adolescents she found teacher support to be the single most influential factor associated with academic effort and achievement.

Direct relationships with regard to the teacher-student relationship and academic performance are also noted within the literature. Valiente, Lemery-Chalfant, Swanson, and Reiser (2008) investigated the impact of teacher-student relationships and academic outcomes. In their results they reported that enhanced teacher-student relationships directly influenced improvements in student GPA and decreases in absenteeism in middle school children. Klem and Connell (2004) investigated students' perceptions of the teacher-student relationship and reported that students who perceived their instructors as promoting a supportive, structured classroom, with fair but high expectations, were significantly more likely to be engaged in school. As a result, these students demonstrated higher attendance rates and stronger test performance. Additionally, Klem 
and Connell reported that students' perceptions of teacher support were significantly associated with student engagement while simultaneously finding that this construct was bi-directional. In other words, results suggested that strong teacher-student relationships promoted student engagement - stimulating higher levels of attention, interest, and persistence - which led to teachers paying more attention to an invested student. Finally, DiLalla, Marcus, and Wright-Phillips (2004) employed a longitudinal study to examine teacher-student relationship characteristics between elementary children and their academic grades as adolescents. Their results indicated that children with dependent or conflicting relationships with their teachers in elementary school were more likely to produce poor grades as adolescents.

\section{Teacher-Student Relationship in Relation to Behavioral and Social Development}

The dynamic of the teacher-student relationship is noteworthy in the emotional development of all children and is especially significant in interventions directed towards adolescents who are either at-risk and/or presenting with EBD (Decker, Dona, \& Christenson, 2007; Meehan, Hughes, \& Cavell, 2003). Within the teacher-student literature the importance of such a dynamic has been noted from early elementary grades through high school and ranging from such issues as adjustment, identity formation, deviant behavior, and dropout prevention (Croninger \& Lee, 2001; Hamman \& Hendricks, 2005; Herrero, Estevaz, \& Musitu, 2006; Pianta, 2001). Beginning in the elementary years, studies suggest links between the teacher-student relationship and positive adjustment and behavior (Baker, 2006; Pianta \& Steinberg, 1992). In these studies, results suggest that children suffering from learning disabilities or behavioral issues were far less likely to initiate and benefit from a strong teacher-student relationship 
than those who were facing such challenges. However, a moderating effect was also present. Children with learning or behavioral issues and who were able to develop a strong teacher-student relationship where much less likely to demonstrate negative externalizing behavior and poor classroom adjustment than equally affected peers who did not develop beneficial teacher-student relationships (Baker; Pianta \& Steinberg).

Wentzel (1998) examined the teacher-student connection among middle schoolaged students in relation to motivation and social skills development. In this study a strong relationship was found between students' perceptions of teacher support and their motivation in regards to pro-social goals and peer relationships. Additionally, Wentzel found a correlation between poor teacher-student dynamics and increased emotional distress on the part of the student. Such findings are particularly important when the middle school years are examined from the perspective of a critical social and emotional transition point (Myers \& Pianta, 2008). Wentzel suggests that middle school teachers who provide consistent structure, support, and emotional investment to students transitioning out of their elementary years help establish a dynamic that engenders positive behavioral and academic outcomes into high school. As a result, teacher support for middle school children could be especially beneficial for young adolescents who have low levels of parental support (Myers \& Pianta).

As students progress into the high-school years the impact of poor attachments, low perceptions of efficacy, and tumultuous living environments can manifest into harmful and deviant behaviors as well as psychological distress (Herrero, Estevaz, \& Musitu, 2006; Voisin et al., 2005; Wentzel, 2002). Therefore, many of the students placed into RTC settings display behaviors which can benefit from a strong teacher- 
student relationship. Resnick and Bearman (1997) investigated high-risk adolescents and reported that adolescents who reported strong teacher-student relationships were less likely to attempt suicide, engage in violent behavior, abuse alcohol or drugs, and experience psychological distress. As an additional finding, Resnick et al. reported that poor teacher-student relationship quality was a better predictor of negative outcomes than adolescents' perceptions of low family connectedness.

Similar results have been reported by Voisin et al. (2005) where adolescents with low levels of connectedness with their teachers were significantly more likely to engage in deviant behaviors than their peers. Voisin's results show that students with poor teacher-student relationships were notably more at-risk of abusing drugs and alcohol, to be sexually active with partners who were under the influence of substances during sex, and have multiple sexual partners. In a study based out of Spain, Herrero, Estevez, and Musito (2006) showed that students with negative teacher-student relationships were more likely to engage in deviant actions such as antisocial and violent behaviors. In addition, Rudasill et al. (2009) examined student-teacher relationship quality in a sample of early adolescents and found that poor student-teacher relationships (marked by higher levels of conflict) increased students' likelihood of engaging in risk-taking behaviors.

As a final example, Croninger and Lee (2001) examined the perceptions of $10^{\text {th }}$ grade students and their teachers in relationship to the development of social capital (e.g. positive relationships within small networks of individuals that can translate into broad societal success) and dropping out. Croninger and Lee's results showed that when adolescents reported positive and trusting relationships with their teachers they were significantly more likely to complete high school. Moreover, when teachers' perceptions 
of their relationships with particular students were strong, those students were more likely to complete high school. Perhaps the most relevant finding from Croninger and Lee's study lies in their discovery that students with higher social capital who were identified as at-risk (due to the presence of sociological risk factors) and/or those who had experienced past academic struggles, were more likely to complete high school then their peers who did not develop the same degree of social capital.

\section{Student-Teacher Relationship and Attachment}

Many studies have demonstrated a link between a child's early attachment style and the strength of the teacher-student relationship (Al-Yagon \& Mikulincer, 2004). Securely attached children are more likely to relate in constructive ways with teachers, demonstrate more attention and socially acceptable behavior in class, and cope more positively with challenging social and academic stressors (Kennedy \& Kennedy, 2004).

On the other hand, children with insecure attachments are more likely to show disruptive classroom behaviors, avoid asking for help from teachers when facing academic or social challenges, and avoid their teachers to the degree that they tend to 'slip through the cracks' (Bergin \& Bergin, 2009). Additionally, Bergin and Bergin point out that insecure childhood attachments can be even more difficult to overcome for teachers of adolescents because students spend a relatively small portion of their academic day with each of their respective teachers.

\section{Gaps in the Teacher-Student Relationship Literature}

Libby et al. (2005) reported that in RTC settings approximately $50 \%$ of an average resident's day is spent within the classroom environment, and only about $13 \%$ is spent within individual, group, or family therapy. In addition, literature on student- 
teacher relationships among at-risk students emphasizes students with EBD or other risk factors, not adolescents placed within RTC settings (see Cavell et al., 2009; Croninger \& Lee, 2001; Meehan, Hughes, \& Cavell, 2003; Voisin, et al., 2005, 2006). While there are notable parallels in risk-factors shared between these populations and RTC residents, the unique blend of clinical, milieu, and academic interventions within the RTC environment limits the generalizability of the current teacher-student relationship literature to students who are placed in RTC settings (Curry, 2004; Foltz, 2004; Frensch \& Cameron, 2002).

\section{Academic Efficacy}

Academic efficacy is a measure of an individual's perceived ability to successfully complete academic tasks (Zimmerman, Bandura \& Martinez-Pons, 1992) and is a uniquely different construct than self-concept. Whereas self-concept centers upon cognitions of 'being' or 'emotion' (e.g. "am I a good partner to my fiancé while I write my dissertation?" or "how do I feel about myself as a person?"), self-efficacy cognitions focus upon the idea of "I can," or "I will" (e.g. "I can earn a promotion," or "I will graduate from high school.” (Pajares \& Schunk, 2001; Schunk, 2001). Bandura (1997) described school as the primary environment where cognitive abilities are promoted and appraised, were self-regulation in relation to a student's environment is developed, and where individuals begin to apply positive or negative schemas to various stimuli within their environment. As a result, critical to the successful application of these themes is the development of academic efficacy.

\section{Academic Efficacy and Achievement}

Zimmerman, Bandura, and Martinez-Pons (1992) examined the impact of academic efficacy upon goal-setting behavior and academic achievement on high-school 
students. While in prior studies of motivational factors students' past grades were the most significant predictor of academic achievement (Schunk, 1984), Zimmerman and colleagues were surprised to find that the predictive relationship of past grades was not statistically significant. Instead finding that students' levels of academic efficacy was the most powerful predictor of overall academic achievement. This result suggests that academic efficacy influences academic achievement and that it also has the potential to be enhanced during a child's academic development, rather than being a fixed constant set at a relatively young age. Further analysis on the part of Zimmerman showed that academic efficacy contributed to a student's ability to self-regulate and set attainable goals.

Roeser, Midgley, and Urdan (1996) conducted a study of 296 middle school students to examine whether perceptions of academic efficacy were related to end-ofsemester grades. Unlike Zimmerman's results, past academic achievement was determined to be the strongest predictor of end-of-semester grades. However, after controlling for past academic achievement, Roeser and colleagues found that students higher in academic efficacy produced stronger end-of-semester results than their peers who had low academic efficacy. Also, when students' self-reported achievement goals in relation to academic efficacy were controlled, self-described achievement goals appeared to relate to facets of efficacy (e.g. motivation and positive learning strategies), validating the impact of academic efficacy upon enhanced goal-setting and academic achievement. Self-efficacy theorists posit that academic efficacy is augmented by virtue of increasing students' sense of competency with repetitions of successful tasks and enhancing confidence via positive modeling and authentic mastery experiences (Pajares 
\& Schunk, 2001; Zimmerman, Bandura, \& Martinez-Pons, 1992). Thus interventions for enhancing academic efficacy should be strategically designed to encourage continued success, reframe failures into positive cognitions, and provide authentic opportunities for learning to occur (Pajares \& Schunk, 2001). Teachers can implement these concepts into practice by helping students develop positive cognitions relative to the classroom environment including: recognizing and teaching fundamental learning strategies, reinforcing effort and motivation, encouraging peers to model and mentor effective learning approaches, and helping students identify, maintain, and complete appropriate academic goals (Margolis \& McCabe, 2004; Ormond, 2003; Pajares, 2003).

\section{Generalizability of Academic Efficacy}

Research suggests that social cognitive theory - by virtue of an individual successfully mastering specific tasks via the utilization of authentic mastery experiences and positive outcome expectations - supports the idea that broad aspects of self-efficacy (e.g. academic efficacy) can be generalized to more discrete arenas (Bong, 1997; Choi, 2005). One study exploring the enhancement of specific math skills (e.g. calculus) via academic efficacy within broad mathematical skills was conducted by Lent, Brown, and Gore (1997). Their results suggested that, within the realm of mathematics, broad academic efficacy did in fact enhance efficacy within more specific subtopics. In another study, Bong (1997) investigated whether the broad academic efficacy of high school students contributed to enhanced efficacy within specific domains of English, Spanish, algebra, chemistry, and geometry. Bong's results suggested that higher-order factors of verbal and math efficacy did in fact account for a significant amount of variance in efficacy scores for these subject specific factors. 


\section{Teacher Efficacy}

Teacher efficacy relates to teachers' perceptions of their ability to influence the academic performance and social development of students within their classrooms, especially with those students who are lacking in personal motivation or academic interest (Tschannen-Moran \& Hoy, 2001). Teacher efficacy has theoretical roots in Bandura's social cognitive theory, which suggests that positive outcome expectations (i.e. "I will find creative methods to assist a difficult student") are enhanced by authentic mastery experiences (i.e. maintaining a positive learning environment within of a class of EBD students) (Bandura, 1986, 1989; Yeo et al., 2008). Social cognitive theory provides a particularly interesting lens in which to examine the impact of a specialized training (e.g. Risking Connection) because such trainings can provide a framework to enhance mastery experiences by virtue of vicarious learning (Bandura, 1986). For example, if a teacher who lacks specific training in de-escalating an aggressive student can observe and practice role plays of successful de-escalation techniques, those techniques can become a part of a repertoire of classroom interventions. Such techniques, in turn, enhance efficacy by altering a situation associated with negative outcome expectations to one which promotes positive outcome expectations (Giller, Vermilyea \& Steele, 2006; Bandura, 1986).

The idea that experience and training can enhance positive outcome expectations, successful mastery experiences, and, as a result, teacher efficacy is supported within the literature (Yeo et al., 2008). For example, Campbell (1996) found that in-service teachers produced higher scores on self-reports of teacher efficacy than pre-service teachers. And within the same study showed that teachers with more than ten years of 
experience reported higher degrees of teacher efficacy than peers who had taught for less than three years. Similar results suggesting an increase in perceived teacher efficacy in relation to years of experience were reported by Wilson and Tan (2004). In their study, teachers who had more than twenty years of teaching experience reported higher perceptions of teacher efficacy than their peers who had taught less than twenty years. De la Torre Cruz and Arias (2007) found that teachers with fifteen years of experience were significantly more efficacious in their ability to maintain student interest and control disruptive behaviors than their peers who were completing student teaching.

\section{Teacher Efficacy and Academic Achievement}

Teacher efficacy has been positively associated with improvements in students' academic achievement and academic efficacy (Goddard et al., 2004; Jinks \& Morgan, 1999; Midgley et al., 1989; Tschannen-Moran \& Barr, 2004). Moore and Esselman (1992) examined achievement scores for the 1990-1991 school year in Kansas City, Missouri against measures of teacher efficacy. Moore and Esselman's results indicated that higher degrees of teacher efficacy were linked to increased student performance in both reading and mathematics achievement. In an example of science courses being impacted by teacher efficacy, Ross (1992) examined the role of teacher efficacy in the implementation of a new science teaching curriculum. At the conclusion of his study the end-of-year grades of middle school students correlated positively with teacher efficacy.

As another example, Midgley, Feldlaufer, and Eccles (1989) conducted a twoyear study with over 1300 adolescents examining the role of teacher efficacy and their students' perceived levels of mathematics efficacy and motivation. Their results indicated that teacher efficacy had a significant impact upon the developing sense of mathematics 
efficacy and motivation of their students. Surprisingly, their study suggested that students who transitioned from teachers high in efficacy to those with lower levels of teaching efficacy had poorer mathematics efficacy and motivation then their peers who had been instructed by low efficacy instructors for two consecutive years.

\section{Collective Teacher Efficacy}

One final facet of teacher efficacy which is relatively new within the literature is collective teacher efficacy (Tschannen-Moran \& Hoy, 2001). Collective teacher efficacy also has roots in social cognitive theory and is a measurement of teacher perception of the ability of the collective faculty at a given educational setting make a difference in the lives of their students over and beyond the influence of their families and local communities (Tschannen-Moran \& Barr, 2004). Goddard, Hoy and Hoy (2004) examined collective efficacy within middle school students and found positive relationships with both academic (math, writing, and English test-taking) skills and classroom management (instructional efficacy and student discipline) outcomes. In a pilot study to examine the reliability and validity of the collective efficacy instrument used within this study, Tschannen-Moran and Barr (2004) examined two factors of collective efficacy (instructional strategies and student discipline). Both factors were positively related to three different measures of student achievement (math, writing, and English).

\section{Restatement of Purpose of Study}

No prior study has examined the domains of teacher efficacy, collective teacher efficacy, resident academic efficacy, and resident perception of the teacher-student relationship in an RTC setting. As a result, the purpose of this study is threefold: (a) to examine whether teachers' individual and collective perceptions of teaching efficacy 
improve after receiving the Risking Connection training, (b) to identify whether residents develop marked improvements in perceived strength of teacher-student relationship and academic efficacy after their teachers receive the Risking Connection training, and (c) to examine - prior to teachers receiving the Risking Connection training - whether teacher efficacy has a positive or negative association with student efficacy and the quality of the teacher-student relationship.

Research Question 1: Will the Risking Connection training enhance teacher efficacy in an RTC setting?

Research Question 2: Will the Risking Connection training increase teacher perception of collective teacher efficacy in relation in an RTC setting?

Research Question 3: After having their teachers receive the Risking Connection training, will students' perceptions of academic efficacy increase?

Research Question 4: After having their teachers receive the Risking Connection training, will students' perceptions of their teacher-student relationship improve? Research Question 5: To what degree is individual and collective teacher efficacy associated with levels of student perception regarding the quality of their teacher/student relationship?

Research Question 6: To what degree is individual and collective teacher efficacy associated with levels of student academic efficacy? 


\section{CHAPTER 3}

\section{METHODOLOGY}

\section{Participants}

Participants within this study consisted of teachers and residents at two different Residential Treatment Centers (RTCs) in Louisville, Kentucky. The first RTC is Brooklawn's, residential care program, an all-boys facility. At Brooklawn seven teachers initially agreed to participate in this study. Demographic data regarding gender, racial identity, subject matter taught, grade level(s) taught, and years of teaching experience were collected. The second RTC is Maryhurst's Euphrasia program, an all-girls facility. At Maryhurst seven teachers initially agreed to participate in this study. Identical demographic information was gathered from the teachers at Maryhurst. At both Maryhurst and Brooklawn, all residents attend on-site academic programs.

Eighty-one boys initially agreed to participate at Brooklawn, ranging in age from 11 to 18 . Demographic information, when available, was provided confidentially by Brooklawn staff. Ninety-three girls initially agreed to participate at Maryhurst, ranging in age from 11 to 18. Demographic information, when available, was provided confidentially by Maryhurst staff. The majority of Brooklawn and Maryhurst's residents are wards of the state due to significant histories of abuse or neglect. Other academic challenges which impact Maryhurst residents include varying levels of mental retardation and reading/writing/mathematical-based learning disabilities. 


\section{Procedures}

Data were collected as part of pilot study conducted by Drs. Kathleen Rudasill, Patrick Poessel, and Natalie Kosine. The primary study was designed to examine the specific impact of the Risking Connection intervention upon teacher behavior in the classroom. The study gained IRB approval (IRB \# 08.0574) from the University of Louisville and from the Jefferson County Public School System in December of 2009. Data were collected at two (teachers) and four (students) time points within a five-month period which began in January, 2009. Standardized instructions, approved within the original IRB, were provided to all subjects prior to each administration of assessment materials. All subjects were reminded prior to each assessment session of their right to not participate in the study.

Procedures included the administration of self-report surveys to both teachers and students. Prior to data collection, consent forms were provided to the teachers and assent forms were explained to the residents. As an incentive, residents were provided pizza lunches and soft drinks as compensation for their time at the completion of each administration session. For the purpose of the current study, data were collected as a subsidiary component of the pilot study. As a result, the data currently exist in an archival state and did not require further IRB review.

\section{Study Design}

The study design is a quasi-experimental, pretest-posttest design utilizing data collected by way of two phases over the course of five months. Student data were collected via a double pretest and double posttest design while teachers completed one pretest and one posttest. This variation in design was implemented because adolescence 
is a period marked by rapid changes in mood, affect, and the development of critical thinking skills, especially within an RTC setting (Baker \& Curtis, 2006; Walter \& Petr, 2007). Thereby, the double pretest/double posttest format helped to control for any possible student fluctuations which did not occur as a direct product of their teachers receiving the Risking Connection intervention.

\section{Resident Administrations}

Phase I (see Figure 1.) consisted of two separate pretest administrations with approximately two and one-half months of separation. Both pretest administrations occurred prior to the residents' teachers receiving the Risking Connection intervention.

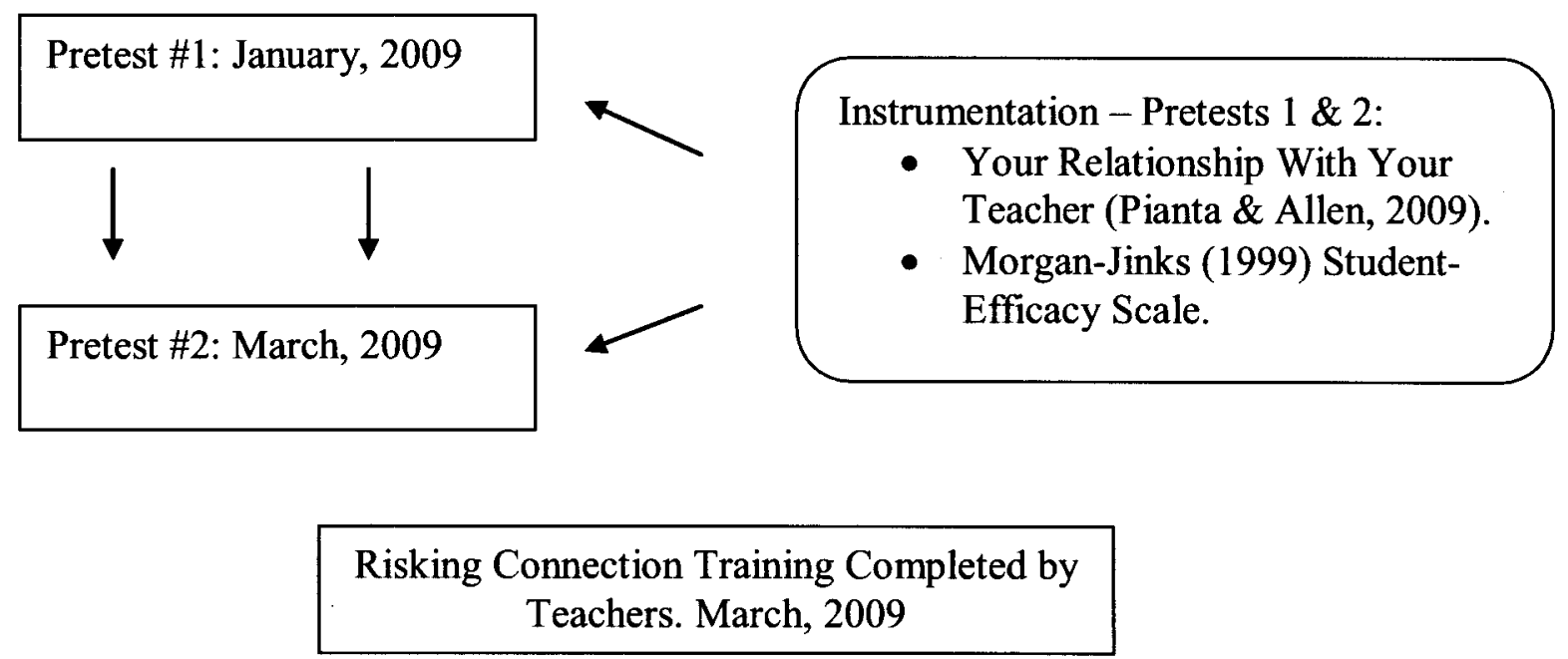

Figure 1. Diagram of Phase I: Student pretest administrations.

Phase II (See Figure 2.) was initiated one month after residents' teachers had completed the Risking Connection training. Phase II consisted of the administration of two separate posttests which were separated by approximately two months. As with the dual double pretests, the utilization of two separate posttests served to control for 
fluctuation in students' results as time passed from the implementation of their teachers' Risking Connection training.

\section{Risking Connection Training Completed by}

Teachers. March, 2009

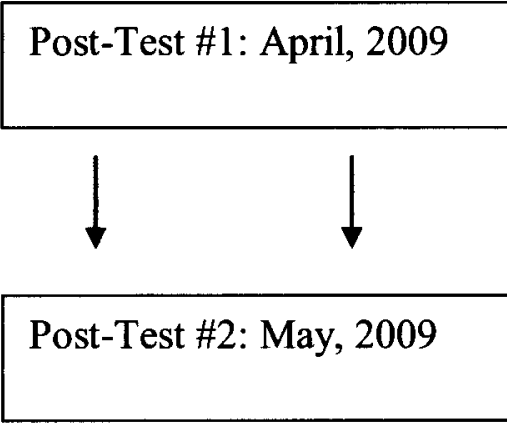

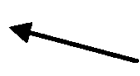

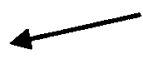

Instrumentation - Pretests $1 \& 2$ :

- Your Relationship With Your Teacher (Pianta \& Allen, 2009).

- Morgan-Jinks (1999) StudentEfficacy Scale.

Figure 2. Diagram of Phase II: Student posttest administrations.

\section{Teacher Administrations}

Unlike the students, only one pretest and one posttest was administered to the teachers. Teachers were administered their pretest at the same time as the students received their initial pretest. The Risking Connection training occurred approximately two and one-half months after the initiation of the study. Two and one-half months after the completion of the Risking connection training, teachers completed their posttest at the same time in which the students were administered their final posttest. 


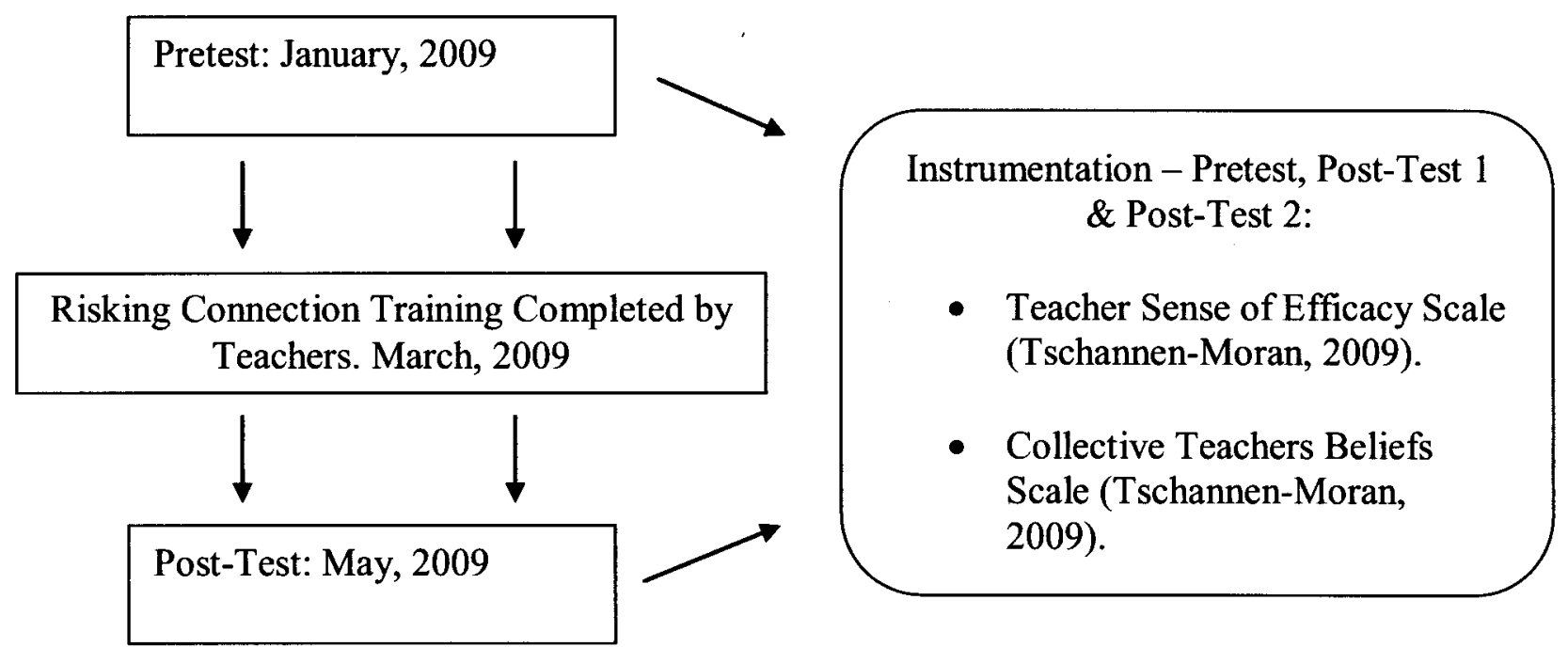

Figure 3. Timeline of teacher pretest and posttest

\section{Measures}

\section{Resident-Based Instrumentation}

\section{Your Relationship with this Teacher Scale}

This self-report instrument is designed to examine the perceptions of secondary students' relationships with a specific teacher and uses a four and five-item answer format (either $a .=$ Not At All True; $b .=$ Somewhat True; $c .=$ True; and $d .=$ Very True or $\mathbf{a} .=$ Almost Never; $\mathrm{b} .=$ Rarely; $\mathrm{c} .=$ Sometimes; $\mathrm{d} .=$ Often; and $\mathrm{e} .=$ Almost Always $)$. The Your Relationship with this Teacher Scale has been adapted from three different instruments (Skinner \& Belmont, 1993; Roeser, Eccles, \& Sameroff, 1998; Gregory \& Weinstein, in press) and is being used as part of the MyTeachingPartner-Secondary teacher research/development program (Pianta \& Allen, 2009).

Questions centering on students' perception of respect and affection were developed by Skinner and Belmont (1993) and consist of items such as "This teacher likes me," and "This teacher really cares about me." Skinner and Belmont reported a 
Cronbach's alpha $=.79$ for their items. Questions centering on students' perception of trust were developed by Gregory and Weinstein (in press) and consisted of items such as "This teacher never listens to my side." Gregory and Weinstein reported a Cronbach's alpha $=.91$ for their items. Questions centering on students' perception of differential attention were developed by Roeser, Eccles, and Sameroff (1998) and consisted of items such as "This teacher thinks I am less smart than I really am because of my race." Roeser, Eccles, and Sameroff reported Cronbach's alphas ranging from .70 to .84 for their items. To control for nuisance variables - which could occur by virtue of examining students within one specific classroom or dormitory setting - this measure was modified to be administered within a broad group format. As a result, the phrase "My first period teacher" was substituted for "This teacher" within all items prior to administration. Within this study, Cronbach's alphas ranged from .80 to .86 for Your Relationship with this Teacher Items.

\section{Morgan Jinks Student Efficacy Scale}

The Morgan-Jinks Student Efficacy Scale (MJSES) is a self-report measure of students' generalized academic efficacy (Jinks \& Morgan, 1999). The instrument consists of 30 items and uses a four-point Likert Scale $(1=$ Really Agree, $2=$ Kind of Agree, $3=$ Kind of Disagree, and $4=$ Really Disagree.). During instrument design, informal response descriptors were used within the MJSES to relate with language patterns used by children and adolescents. Field tests were undertaken from three different schools with widely varying ethnic and socioeconomic student populations. Also, the three schools represented urban, suburban, and rural geographic locations. Factor analysis revealed three discrete factors within the scale (no Eigenvalues were reported) with non-loading 
items being discarded. Additionally, any item with an item-total item correlation below .30 was also discarded (Jinks \& Morgan, 1999). Internal consistency values and subscale titles are discussed below.

The MJSES provides a general Academic Efficacy score $(\alpha=.82)$ and three subscales. The first subscale, Talent, has a reliability coefficient of $\alpha=.78$ and consists of items such as "It is not hard for me to get good grades in school." The second subscale, Context, has a reliability coefficient of $\alpha=.70$ and is made up of items such as "I would make better grades if my teacher liked me better." The final subscale, identified as Effort, has a reliability coefficient of $\alpha=.66$ and includes items such as "I always get good grades when I try hard." Additionally, Jinks and Morgan (1999) reported that the MJSES and its subscales have a moderately positive correlation with self-reported grades. Within this study, Cronbach's alphas ranged from .47 to .88 for MJSES items.

\section{Teacher-Based Instrumentation}

\section{Collective Teacher Beliefs Scale}

Collective efficacy is a measurement of perception that faculty in a given educational setting make a difference in the lives of their students over and beyond the influence of outside caregivers (Tschannen-Moran \& Barr, 2004). The Collective Teacher Beliefs Scale (Tschannen-Moran, 2009) measures teachers' perceptions as to the degree of efficacy that exists among their peers as a collective faculty. The scale consists of 12 items and utilizes a nine-point Likert scale (ranging from $1=$ None At All, to $9=A$ Great Deal). Results are interpreted via a global measurement of Collective Efficacy and also by virtue of two subscales, Student Discipline and Instructional Strategies. In a field study of 49 middle schools, internal consistency reliabilities for Collective Efficacy, 
Instructional Strategies, and Student Discipline were $.97, .96$, and .94 respectively (as cited in Allen, 2003). In a separate study, Tschannen-Moran and Barr (2004) reported statistically significant positive relationships between Collective Efficacy, Instructional Strategies, and Student Discipline with three different measures of student achievement (math, writing, and English). Within this study, Cronbach's alphas ranged from .86 to .94 for the Collective Teacher Beliefs scale.

\section{Teacher Sense of Efficacy Scale}

The Teacher Sense of Efficacy Scale (TSES) is designed to measure teachers' self-perceptions of their capacity to utilize successful instructional strategies, actively engage students, and positively manage the classroom (Tschannen-Moran, 2009). The scale consists of 12 items has a nine-point Likert scale (ranging from $1=$ None At All, to $9=\mathrm{A}$ Great Deal). Results are interpreted via a global measurement of Teacher Efficacy and also provide subscales measuring Instructional Efficacy, Classroom Management Efficacy, and Student Engagement Efficacy. Tschannen-Moran and Hoy (2001) reported strong internal consistency reliabilities for the Teacher Efficacy $(\alpha=.90)$, Instructional Efficacy $(\alpha=.86)$, Classroom Management Efficacy $(\alpha=.86)$, and Student Engagement Efficacy $(\alpha=.86)$. In addition, Tschannen-Moran and Hoy (2001) examined the validity of the three subscales via factor analysis reporting Eigenvalue $=10.38$ for Instructional Efficacy, Eigenvalue $=2.03$ for Classroom Management, and Eigenvalue $=1.62$ for Student Engagement. Within this study, Cronbach's alphas ranged from .43 to .78 for TSES items. 


\section{Data Analysis}

\section{Preliminary Considerations}

Data were analyzed via mixed-model ANOVAs and multiple regression. First, assumptions (normality of distributions, linearity, multicollinearity, and homoscedastcity) were examined to determine if any analytic concerns associated with ANOVA or multiple regression were present. Additionally, in respect to Pedhazur's (1997) preliminary guidelines for conducting regression analyses, descriptive statistics (e.g. means, standard deviations, and ranges) were examined. These data informed how to best interpret each distribution (e.g. adjust to a dichotomous variable or leave as a continuous variable) and helped identify possible outliers.

Given the relatively low $(n=13)$ number of teachers, a power analysis was conducted using Faul, Erdfelder, Lang, and Buchner's (2007) G*Power 3 power analysis program. The power analysis was conducted assuming the following parameters: $\alpha=.05$, Power $(1-\beta)=.95$, sample size $=13$, number of groups $=2$, and number of repetitions $=$ 2. Based on these criteria, to meet statistical significance teacher-response results required a critical $F$ of $(1,11)=4.844$ and an effect size of $f=.954$. When examining this power analysis in reference to the small sample size of the teacher group, it appears unlikely that the required effect size to reach statistical significance will occur.

Additional power analyses were conducted with the $\mathrm{G}^{*}$ Power 3 power analysis program to determine whether the existing student samples sizes were appropriate to use with mixed-model ANOVA and multiple regression (Faul et al., 2007). Concerning ANOVA, estimating for an effect size of $f=.25, \alpha=.05$, Power $(1-\beta)=.95$, number of groups $=2$, and number of repetitions $=4$; power analysis specifies that an $n=36$ would 
be an adequate minimum sample size. Sixty total subjects completed all four test administrations (as required for the within-subjects component of mixed-model ANOVAs), the power analysis indicated that the sample size was adequate for this study. Concerning multiple regression, estimating for an effect size of $f=.15, \alpha=.05$, Power ( 1 $-\beta)=.95$, and number of predictors $=3$; power analysis specifies that an $n=119$ would be required to acquire a critical $F$ of $(3,115)=2.683$. This result indicates that this study's combined sample size of $n=129$ was appropriate for examination via multiple regression.

\section{Analytic Goals}

The investigative objectives of this study are threefold: (a) to examine whether teachers' perceptions of self-efficacy (both individually and of their peers) in an acute residential treatment setting can be enhanced through the Risking Connection training, (b) to identify whether residents develop marked improvements in perceived strength of teacher-student relationships and academic efficacy after teacher training, and (c) to examine - prior to teachers receiving the Risking Connection training - whether teacher efficacy has a positive or negative association with student efficacy and the strength of the teacher-student relationship.

\section{Objective 1: To examine whether teachers' individual and collective} perceptions of efficacy improve after receiving the Risking Connection training.

This objective was met by using two mixed-model ANOVAs. The first ANOVA was calculated with separate administrations (e.g. pretest and posttest) as the withinsubjects independent variable, the two programs (Brooklawn and Maryhurst) as the between-subjects independent variable, and scores on the Teacher Sense of Efficacy 
Scale as the dependent variable. The second ANOVA was calculated with separate administrations (e.g. pretest and posttest) as the within-subjects independent variable, the two programs (Brooklawn and Maryhurst) as the between-subjects independent variable, and scores on the Collective Teacher Beliefs Scale as the dependent variable.

Objective 2: To identify whether residents develop marked improvements in perceived strength of student-teacher relationship and academic efficacy after their teachers receive the Risking Connection training.

This objective was met with two mixed-model ANOVAs. The first ANOVA was calculated utilizing separate administrations (e.g. pretest one, pretest two, posttest one, and posttest two) as the within-subjects independent variable, the two programs (Brooklawn and Maryhurst) as the between-subjects independent variable, and scores on the Your Relationship with this Teacher Scale as the dependent variable. The second ANOVA was calculated with separate administrations (e.g. pretest one, pretest two, posttest one, and posttest two) as the within-subjects independent variable, the two programs (Brooklawn and Maryhurst) as the between-subjects independent variable, and scores on the Morgan-Jinks Student Efficacy Scale as the dependent variable. No ANOVA results with more than two means were significant, thus post hoc measures such as Tukey's HSD were not required for Objective 2 .

Objective 3: To examine - prior to teachers receiving the Risking Connection training - whether individual and collective teacher efficacy has a positive or negative association with the quality of the teacher/student relationship and student efficacy. 
This objective was met with four multiple regression analyses between the residents' combined responses on pretest one and pretest two with the teachers' results on pretest one. To prevent any positive effect of students' continued placement in an RTC setting on pretest results, only students' first test administration within Phase I were used. Thus scores from the first administration were used for students who were enrolled at Brooklawn or Maryhurst for the administration of pretest one, while scores from pretest two were used only for students who enrolled at Brooklawn or Maryhurst after the administration of pretest one, but were present for pretest two. Additionally, because the student instruments were adapted to a group format (emphasizing each subject's first period teacher), the regression analyses connected student results to those of their first period teachers.

The first analysis regressed student pretest results from the Your Relationship with this Teacher Scale on three different predictor variables. The predictor variables were: pretest results from the Teacher Sense of Efficacy Scale, pretest results from the Collective Teacher Beliefs Scale, and RTC site (Brooklawn or Maryhurst). The second, third, and fourth analyses regressed student pretest results from three separate subscales of the Morgan-Jinks Student Efficacy Scale (Talent, Context, and Effort). As with the first regression, each subscale was regressed on three different predictor variables. The predictor variables were: pretest results from the Teacher Sense of Efficacy Scale, pretest results from the Collective Teacher Beliefs Scale, and RTC site (Brooklawn or Maryhurst). 


\section{CHAPTER 4}

\section{RESULTS}

As stated in Chapter 1, no prior study has examined the domains of teacher efficacy, collective teacher efficacy, resident academic efficacy, and resident perception of the teacher-student relationship in an RTC setting. In addition, no study has used an RTC setting to investigate the impact of a theory-driven, specialized training upon teachers' individual and collective perceptions of efficacy, residents' self-perceptions of individual academic efficacy, and residents' relationships with their teachers. The results of the study are presented following the six specific research questions outlined at the end of Chapter 1, and are further organized by the three specific analytic objectives outlined within Chapter 3.

\section{Teacher Characteristics}

Thirteen of the 14 teachers who initially agreed to participate in the study completed both the pretest and posttest administrations. Of the 13 teachers who completed both phases of this study 12 were female and 1 was male. Eight (62\%) of the teachers identified themselves as Caucasian, two (15\%) as African American, one (8\%) as "Other," and two (15\%) did not complete demographic items. Concerning subject matter taught, two teachers specialized in each of the following: math, science, language arts, and social studies; three teachers listed their area of specialization as "All." The number of years of teaching experience ranged from 1 to 38 years (Overall $M=9.5, S D=$ 8.0; Brooklawn $M=10.28, S D=9.50$; Maryhurst $M=8.4, S D=6.19$ ). 


\section{Objective 1: To Examine Whether Teachers' Individual and Collective Perceptions}

of Teaching-Efficacy Improve After Receiving the Risking Connection Training

Two mixed-model ANOVAs were conducted to examine research questions specific to Objective 1. Prior to interpreting results, assumptions of independence, normality, homogeneity of variance, and homogeneity of covariance (sphericity) were examined. On both of the ANOVAs the sphericity assumption was violated due to Mauchly's W Test of Sphericity having a $\chi^{2}(0)=.00, p<.01$. To compensate for this violation and reduce the risk of Type I error, the Greenhouse-Geisser adjustment was used to examine $F$ values for these ANOVAs. No other violations of mixed-model ANOVA occurred within these analyses.

\section{Research Question 1: Will the Risking Connection training enhance teacher}

\section{efficacy in an RTC Setting?}

A mixed-model ANOVA using the pretest and posttest administrations as the within-subjects variable, Maryhurst and Brooklawn as the between-subjects variable, and scores on the Teacher Sense of Efficacy Scale as the dependent variable was conducted (Tables 1 and 2). There were no significant effects for the between-subjects variables $(F$ $(1,11)=.782, \mathrm{p}=.395)$ or the within-subjects variables $\left(F_{(1,11)}=.272, \mathrm{p}=.612\right)$. The interaction of the within and between-subjects variables $\left(F_{(1,11)}=3.955, \mathrm{p}=.072\right)$, however, neared significance and is worthy of review given the relatively small sample size. 
Table 1

Means and Standard Deviations for the Teacher Sense of Efficacy Scale

\begin{tabular}{lccc}
\hline Administration & Combined $(N=13)$ & Brooklawn $(N=7)$ & Maryhurst $(N=6)$ \\
\hline Pretest & & & \\
$M$ & 7.055 & 7.036 & 7.078 \\
$S D$ & .890 & .901 & .961 \\
Posttest & & & \\
$M$ & 6.918 & 6.524 & 7.378 \\
$S D$ & 1.083 & 1.135 & .893 \\
\hline
\end{tabular}

Table 2

Mixed-Model Analysis of Variance Results for the Teacher Sense of Efficacy Scale

\begin{tabular}{|c|c|c|c|c|c|}
\hline Source & $d f$ & $S S$ & $M S$ & $F,(p$ Value $)$ & $\omega^{2}$ \\
\hline \multicolumn{6}{|c|}{ Between Subjects } \\
\hline RTC & 1 & 1.298 & 1.298 & $.782,(p=.395)$ & -.017 \\
\hline Error & 11 & 2.956 & .269 & & \\
\hline \multicolumn{6}{|c|}{ Within Subjects } \\
\hline Admin. (A) & 1 & .073 & .073 & $.272,(p=.612)$ & -.045 \\
\hline $\mathrm{A} * \mathrm{RTC}$ & 1 & 1.063 & 1.063 & $3.955(p=.072)$ & .182 \\
\hline Error & 11 & 2.956 & .269 & & \\
\hline
\end{tabular}

Note. All $F$ values interpreted with the Greenhouse-Geisser correction.

Omega-squared $\left(\omega^{2}\right)$ effect size analyses were calculated with each variable from this ANOVA. The $\omega^{2}$ for test administration * $\mathrm{RTC}=.182$, meaning that approximately 
$18.2 \%$ of the variance in Teacher Efficacy was accounted for by the interaction between administration time and RTC program. Although ANOVA results did not indicate statistical significance, according to Cohen (1988) this is a medium-sized effect. Figure 4 illustrates this effect by presenting trends from pretest to posttest between Brooklawn and Maryhurst. All other $\omega^{2}$ effects, due to having a negative value, were equal to zero.

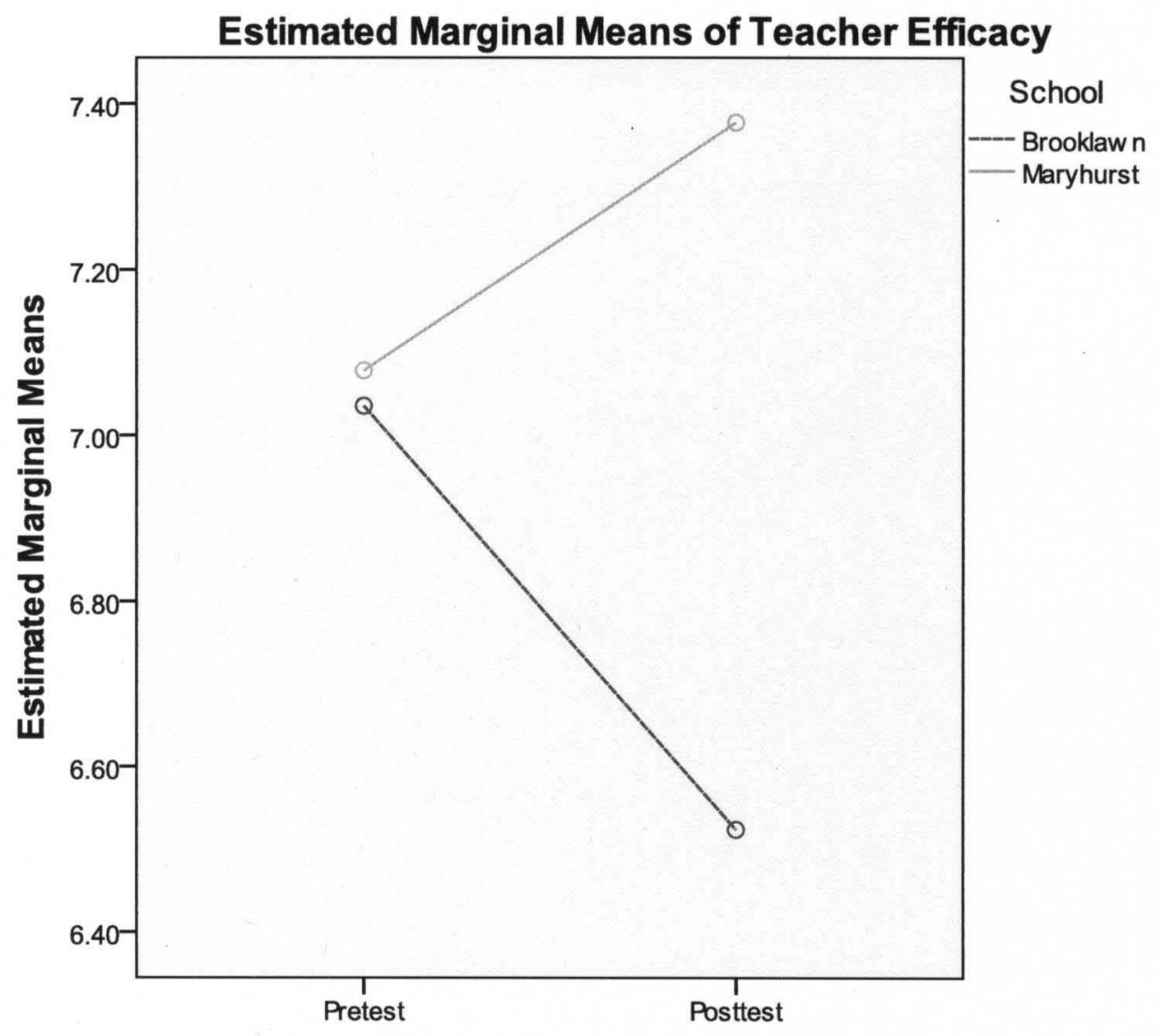

Administration

Figure 4. Trends in Teacher Efficacy mean scores from pretest to posttest.

As this figure demonstrates, teachers' ratings of efficacy were similar across RTC programs at the pretest period. However, at posttest Maryhurst's teacher efficacy scores were much higher than those at Brooklawn. 


\section{Research Question 2: Will the Risking Connection training increase teacher} perception of collective teacher efficacy in an RTC setting?

A mixed-model ANOVA using the pretest and posttest administrations as the within-subjects variable, Maryhurst and Brooklawn as the between-subjects variable, and scores on the Collective Teacher Beliefs Scale as the dependent variable was conducted (Tables 3 and 4). There were no significant effects for the between-subjects variables ( $F$ $(1,11)=.295, \mathrm{p}=.598)$ or the interaction of the within and between-subjects variables $(F$ $(1,11)=.110, p=.746)$. The within-subjects effect for collective efficacy, however, was significant $\left(F_{(1,11)}=.2 .009, \mathrm{p}=.053\right)$. Post hoc analysis of pretest $(M=7.22)$ and posttest $(M=6.66)$ scores indicate that a significant decrease in teachers' perceptions of collective efficacy occurred over time.

Table 3

Means and Standard Deviations for the Collective Teachers Beliefs Scale

Administration $\quad$ Combined $(N=13) \quad$ Brooklawn $(N=7) \quad$ Maryhurst $(N=6)$

Pretest

$M$

7.224

7.119

$S D$

1.115

1.437

.686

Posttest
$M$
6.660
6.476
6.875
$S D$
1.085
1.380
.658 
Table 4

Mixed-Model Analysis of Variance Results for the Collective Teachers Beliefs Scale

\begin{tabular}{|c|c|c|c|c|c|}
\hline Source & $d f$ & $S S$ & $M S$ & $F,(p$ Value $)$ & $\omega^{2}$ \\
\hline \multicolumn{6}{|c|}{ Between Subjects } \\
\hline RTC & 1 & .635 & .635 & $.295,(p=.598)$ & -.057 \\
\hline Error & 11 & 23.653 & .2 .150 & & \\
\hline \multicolumn{6}{|c|}{ Within Subjects } \\
\hline Admin. (A) & 1 & 2.009 & 2.009 & $4.711,\left(p=.053^{*}\right)$ & .220 \\
\hline $\mathrm{A} * \mathrm{RTC}$ & 1 & .047 & .047 & $.110(p=.746)$ & -.053 \\
\hline Error & 11 & 4.690 & .426 & & \\
\hline
\end{tabular}

Note. All F values interpreted with the Greenhouse-Geisser correction.

Omega-squared $\left(\omega^{2}\right)$ effect size analyses were calculated with each variable from this ANOVA. The $\omega^{2}$ for administration $=.220$, meaning that approximately $22 \%$ of the variance in Collective Teacher Efficacy is accounted for by differences between pretest and posttest. According to Cohen (1988), this is a medium-sized effect. All other $\omega^{2}$ effects, due to having a negative value, were equal to zero.

\section{Student Characteristics}

One hundred seventy-four students participated in this study. Eighty-one (47\%) were male and $93(53 \%)$ were female. The average age of the subjects was 15.4 years $(S D=1.65)$. Grade level ranged from $5^{\text {th }}$ to $12^{\text {th }}$ grade. Table 5 outlines the ethnicity and representation within special populations of the participants. 
Table 5

Demographic Characteristics of Student Participants $(N=174)$

\begin{tabular}{lllllll}
\hline Demographic & Total $N$ & $\%$ & Brooklawn N $\%$ & Maryhurst N $\%$ \\
\hline Ethnicity & 105 & 60 & 59 & 72 & 46 & 49.9 \\
Caucasian & & & & & & \\
African American & 27 & 15.4 & 13 & 15.9 & 14 & 14.9 \\
Asian/Pacific & 1 & .6 & 0 & 0.0 & 1 & 1.1 \\
Other/unknown & 41 & 23.6 & 9 & 12 & 32 & 34 \\
Special population & & & & & & \\
EBD & 88 & 50.6 & 22 & 27.2 & 60 & 64.5 \\
Cog. deficiency & 13 & 7.5 & 5 & 6.1 & 8 & 8.6 \\
LD & 4 & 2.3 & 2 & 2.5 & 2 & 2.2 \\
Physical impairment13 & 7.7 & 11 & 13.6 & 2 & 2.2 \\
Autism & 2 & 1.1 & 2 & 2.5 & 0 & 0.0 \\
IEP & 70 & 40.2 & 46 & 56.8 & 24 & 25.8 \\
\hline
\end{tabular}

Note. Percentiles for Special population categories exceed $100 \%$ due to some students having multiple diagnoses. EBD (Emotional/Behavioral Disorders) includes mood disorders, PTSD, oppositional defiant, impulse control, ADHD, reactive attachment, and substance abuse disorders. 


\section{Objective 2: To Identify Whether Residents Develop Marked Improvements}

in Perceived Strength of Teacher-Student Relationship and Academic Efficacy After their Teachers Receive the Risking Connection Training

Two mixed-model ANOVAs were used to examine research questions specific to Objective 2. Prior to interpreting results, assumptions of independence, normality, homogeneity of variance, and homogeneity of covariance (sphericity) were examined. On both of the ANOVAs the sphericity assumption tested by Mauchly's W Test of Sphericity was violated. The first ANOVA produced a $\chi^{2}(5)=67.507, \mathrm{p}<.01$, while the second ANOVA produced a $\chi^{2}(5)=.22 .183, \mathrm{p}<.01$. To compensate for this violation and reduce the risk of Type I error, the Greenhouse-Geisser adjustment was used to examine $F$ values for these ANOVAs. No other violations of mixed-model ANOVA occurred within these analyses.

\section{Research Question 3: After having their teachers receive the Risking} Connection training, will students' perceptions of academic efficacy increase?

A mixed-model ANOVA using the two pretest and two posttest administrations as the within-subject variables, Maryhurst and Brooklawn as the between-subjects variable, and scores on the Morgan-Jinks Student Efficacy Scale as the dependent variable was conducted (Tables 6 and 7). There were no significant effects for the between-subjects variables $\left(\mathrm{F}_{(1,58)}=1.830, \mathrm{p}=.181\right)$, the within-subjects variables $\left(F_{(1.672,96.953)}=.272, \mathrm{p}\right.$ $=.722)$, or the interaction of the within and between-subjects variables $\left(F_{(1.672,96.953)}=\right.$ $1.520, \mathrm{p}=.225)$. Omega-squared $\left(\omega^{2}\right)$ effect size analyses were calculated with each variable from this ANOVA. No identifiable effect sizes per Cohen (1988) were present. 
Table 6

Means and Standard Deviations for the Morgan-Jinks Student Efficacy Scale

\begin{tabular}{|c|c|c|c|}
\hline Administration & Combined $(N=60)$ & Brooklawn $(N=25)$ & Maryhurst $(N=35)$ \\
\hline \multicolumn{4}{|l|}{ Pretest 1} \\
\hline$M$ & 3.035 & 3.161 & 2.944 \\
\hline$S D$ & .636 & .585 & .664 \\
\hline \multicolumn{4}{|l|}{ Pretest 2} \\
\hline$M$ & 3.031 & 3.144 & 2.950 \\
\hline$S D$ & .624 & .502 & .694 \\
\hline \multicolumn{4}{|l|}{ Posttest 1} \\
\hline$M$ & 3.092 & 3.070 & 3.107 \\
\hline$S D$ & .403 & .441 & .379 \\
\hline \multicolumn{4}{|l|}{ Posttest 2} \\
\hline$M$ & 3.082 & 3.209 & 2.992 \\
\hline$S D$ & .437 & .414 & .436 \\
\hline
\end{tabular}

Table 7

Mixed-Model Analysis of Variance Results for the Morgan-Jinks Student Efficacy Scale

\begin{tabular}{llllll}
\hline Source & $d f$ & $S S$ & $M S$ & $F,(p$ Value $)$ & $\omega^{2}$ \\
\hline \multirow{5}{c}{ Between Subjects } \\
RTC & 1 & 1.274 & 1.274 & $1.830,(\mathrm{p}=.181)$ & .014 \\
Error & 58 & 40.384 & .696 & \\
\hline
\end{tabular}

(Table 7 continues) 
(Table 7 continued)

\begin{tabular}{llcccc}
\hline Source & $d f$ & $S S$ & $M S$ & $F,(p$ Value $)$ & $\omega^{2}$ \\
\hline \multicolumn{5}{c}{ Within Subjects } \\
Admin. (A) & 1.672 & .119 & .071 & $.272,(\mathrm{p}=.722)$ & -.012 \\
A * RTC & 1.672 & .665 & .398 & $1.520(\mathrm{p}=.225)$ & .008 \\
Error & 96.953 & 25.376 & .262 & \\
\hline
\end{tabular}

Note. All $F$ values interpreted with the Greenhouse-Geisser correction.

A visual examination of the profile plot outlining the estimated marginal means of the Morgan-Jinks Student Efficacy Scale suggested unusual slopes across test administrations (Figure 5). As a result, the within-subjects contrast effect was investigated. Contrast results indicated a significant quadratic contrast within the interaction of Brooklawn's and Maryhurst's slopes $\left(F_{(1,58)}=4.533, \mathrm{p}=.037\right)$.

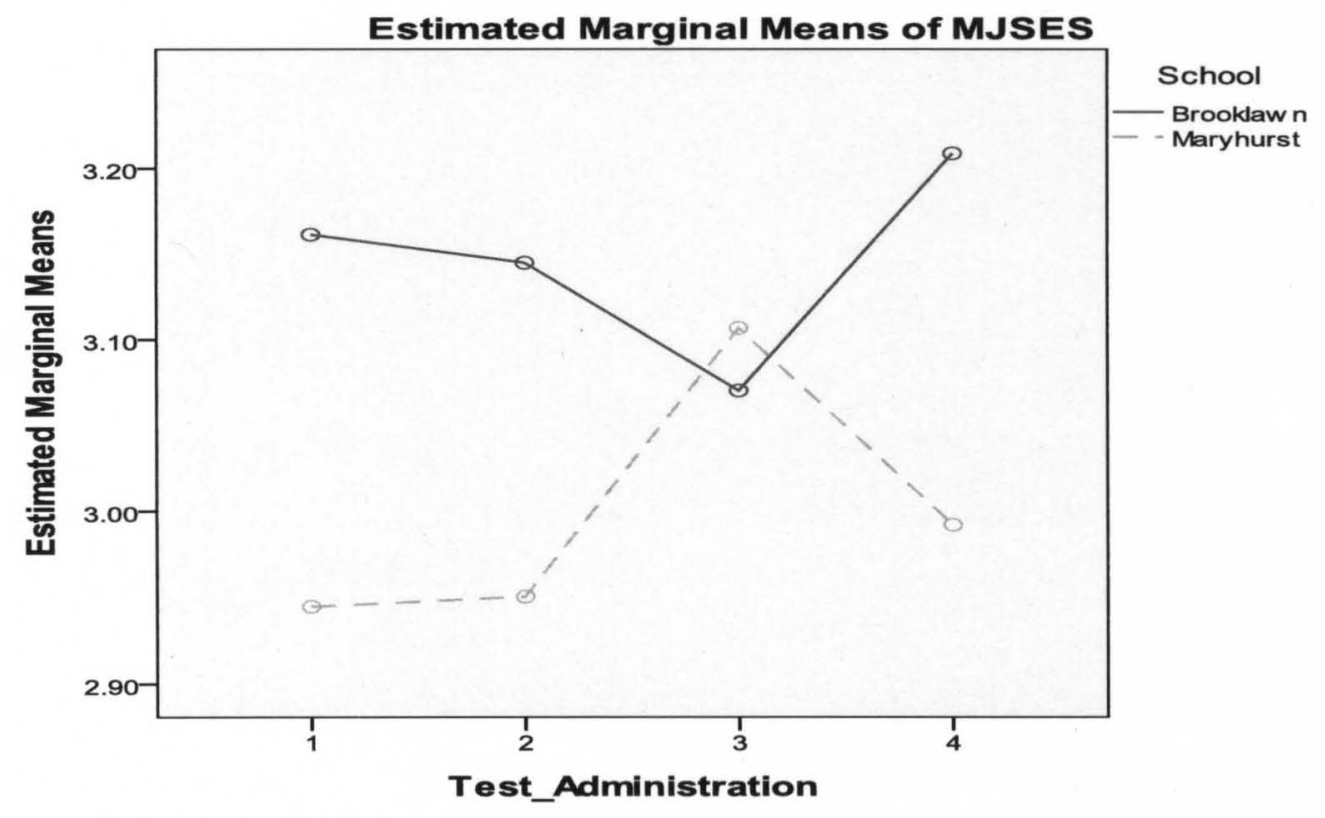

Figure 5. Trends in Academic Efficacy scores from pretest to posttest.

As this figure demonstrates, students in both programs showed a shift in the directions of their respective trends after the first posttest administration. Brooklawn students were 
trending downward in their efficacy scores (over the first three administration periods) but shifted upward for the second posttest while Maryhurst students were trending upward in their efficacy scores (over the first three administration periods) but shifted downward for the second posttest. It is important to point out that this result is not indicative of significant change between test administrations, but instead a significant difference in the two program's trends when examining the interaction between Brooklawn and Maryhurst.

\section{Research Question 4: After having their teachers receive the Risking Connection training, will students' perceptions of their teacher-student relationship improve?}

To examine Research Question 4, a mixed-model ANOVA using the two pretest and two posttest administrations as the within-subject variables, Maryhurst and Brooklawn as the between-subjects variable, and scores on the Your Relationship with this Teacher Scale as the dependent variable was conducted (Tables 8 and 9). There were no significant effects for the between-subjects variables $\left(F_{(1,60)}=.858, \mathrm{p}=.358\right)$, the within-subjects variables $\left(F_{(2.375,142.514)}=.866, \mathrm{p}=.439\right)$, or the interaction of the within and between-subjects variables $\left(F_{(2.375,142.514)}=.518, \mathrm{p}=.628\right)$. Omega-squared $\left(\omega^{2}\right)$ effect size analyses were calculated with each variable from this ANOVA. No identifiable effect sizes per Cohen (1988) were present. 
Table 8

Means and Standard Deviations for the Your Relationship with this Teacher Scale

\begin{tabular}{|c|c|c|c|}
\hline Administration & Combined $(N=62)$ & Brooklawn $(N=27)$ & Maryhurst $(N=35)$ \\
\hline \multicolumn{4}{|l|}{ Pretest 1} \\
\hline$M$ & 3.709 & 3.674 & 3.736 \\
\hline$S D$ & .760 & .598 & .872 \\
\hline \multicolumn{4}{|l|}{ Pretest 2} \\
\hline$M$ & 3.763 & 3.693 & 3.817 \\
\hline$S D$ & .797 & .671 & .888 \\
\hline \multicolumn{4}{|l|}{ Posttest 1} \\
\hline$M$ & 3.845 & 3.686 & 3.971 \\
\hline$S D$ & .633 & .750 & .504 \\
\hline \multicolumn{4}{|l|}{ Posttest 2} \\
\hline$M$ & 3.665 & 3.642 & 3.683 \\
\hline$S D$ & .786 & .851 & .745 \\
\hline
\end{tabular}


Table 9

Mixed-Model ANOVA Results for the Your Relationship with this Teacher Scale

$\begin{array}{llllll}\text { Source } & d f & S S & M S & & \omega^{2}\end{array}$

\begin{tabular}{llcccc}
\hline \multicolumn{5}{c}{ Between Subjects } \\
RTC & 1 & .998 & .998 & $.858,(\mathrm{p}=.358)$ & -.002 \\
Error & 60 & 69.832 & 1.164 & \\
\hline & \multicolumn{5}{c}{ Within Subjects } \\
Admin. (A) & 2.375 & .934 & .393 & $.866,(\mathrm{p}=.439)$ & -.002 \\
A * RTC & 2.375 & .559 & .236 & $.518,(\mathrm{p}=.628)$ & -.008 \\
Error & 142.514 & 64.755 & .454 & & \\
\hline
\end{tabular}

Note. All $F$ values interpreted with the Greenhouse-Geisser correction.

Objective 3: To Examine - Prior to Teachers Receiving the Risking Connection

Training - Whether Individual and Collective Teacher Efficacy Has a Positive or

Negative Association with the Quality of the Teacher/Student Relationship and

Student Efficacy

Four multiple regression analyses were used to examine research questions

specific to Objective 3. Prior to interpreting results, assumptions of linearity, homoscedasticity, normality of residuals, and collinearity (via VIF and tolerance) were examined. Additionally, the potential for outliers was examined via both Pedhazur's (1997) preliminary regression guidelines (e.g. means, standard deviations, and ranges) and Cook's D residual statistic. All four multiple regression analyses were within acceptable limits regarding these assumptions. Therefore no transformations or other adjustments to the data were necessary. 


\section{Research Question 5: To what degree are individual teacher efficacy,}

collective teacher efficacy, and RTC site associated with levels of student perception regarding the quality of their teacher/student relationship?

One hundred twenty-nine student results were evaluated using simultaneous regression to examine whether predictor variables had an impact upon students' perceptions of relationship strength with their first period teachers. The three predictor variables were: teacher efficacy, collective teacher efficacy, and RTC site. Correlations (Table 10) show that teacher and collective teacher efficacy were at or near significance with the dependent variable. Trends, however, between these predictors were moving in opposite directions. The correlation between teacher efficacy and teacher/student relationship was negative $(r=-.237, p=.003)$, while the correlation between collective teacher efficacy and teacher/student relationship was positive $(r=.141, p=.055)$. In addition, the predictors were moderately correlated with each other $(\mathrm{r}=.449, \mathrm{p}<.001)$, suggesting a certain degree of multicollinearity between the predictors. 
Table 10

Means, Standard Deviations, and Correlations for Your Relationship with this Teacher Scale and Predictor Variables

\begin{tabular}{llllll}
\hline Variable & $M$ & $S D$ & 1 & 2 & 3 \\
\hline Relationship w/ Teacher & 3.873 & .598 & $-.237^{* *}$ & $.141^{*}$ & .086 \\
$\quad$ Predictor Variable & & & & & \\
1. Teacher efficacy & .031 & .806 & -- & $.449^{* *}$ & .108 \\
2. Coll. teacher efficacy & 7.112 & 1.050 & -- & -- & .133 \\
3. RTC site & -- & -- & -- & -- & -- \\
\hline
\end{tabular}

${ }^{*} p \leq .055 .{ }^{* *} p<.01$

Table 11 shows results from the simultaneous regression analysis. The model was significant at $F_{(2,126)}=6.792, \mathrm{p}<.001$. The adjusted $\mathrm{R}$ squared for the regression equation was .120 indicating that approximately $12 \%$ of the variance in teacher/student relationship was predicted from teacher efficacy and collective teacher efficacy. When the results of Table 11 are examined in relation to the correlational trends from Table 10 (teacher efficacy trending negatively and collective teacher efficacy trending positively), we can see that students whose teachers had lower individual efficacy and higher collective efficacy scores had higher student-teacher relationship scores. 
Table 11

Predicting Scores on Your Relationship with Teacher (RWT) Scale from Individual Teacher Efficacy, Collective Teacher Efficacy, and RTC Location.

RWT

\begin{tabular}{lll} 
& \multicolumn{2}{c}{$\Delta R^{2}=.120 * * *$} \\
\cline { 2 - 3 } & $\beta$ & $t$ \\
Teacher efficacy & -.381 & $-4.100^{* * *}$ \\
Collective teacher efficacy & .301 & $3.226^{* *}$ \\
RTC site & .087 & 1.037
\end{tabular}

${ }^{*} p<.05 .{ }^{* *} p<.01{ }^{* * *} p<.001$.

Research Question 6: To what degree are individual teacher efficacy, collective teacher efficacy, and RTC site associated with levels of student academic efficacy?

One hundred twenty-nine student results were evaluated using simultaneous regression to examine whether predictor variables had an impact upon students' perceptions of academic efficacy, specifically the three subscales of the Morgan-Jinks Student Efficacy Scale (Talent, Context, and Effort). As with Research Question 5, these subscales were connected to each student's first period teacher using teacher efficacy, collective teacher efficacy, and RTC site as predictor variables. Correlations (Table 12) show that only one statistically significant correlation occurred between predictor variables and a dependent variable in this series of regressions (teacher efficacy with Context, $r=-.147, p=.048$ ). In addition, the predictors were moderately correlated with 
each other $(\mathrm{r}=.459, \mathrm{p}<.001)$, suggesting a certain degree of multicollinearity between the predictors.

Table 12

Means, Standard Deviations, and Correlations for Morgan-Jinks Academic Efficacy Subscales and Predictor Variables

\begin{tabular}{llllll}
\hline Variable & $M$ & $S D$ & 1 & 2 & 3 \\
\hline MJSE talent & 3.107 & .518 & -.011 & -.016 & .120 \\
1. Teacher efficacy & 7.035 & .808 & -- & $.459^{* *}$ & -.113 \\
2. Coll. teacher efficacy & 7.102 & 1.047 & -- & -- & -.125 \\
3. RTC site & -- & -- & -- & -- & -- \\
MJSE context & 3.210 & .537 & $-.147^{*}$ & -.110 & -.085 \\
1. Teacher efficacy & 7.035 & .808 & -- & $.459^{* *}$ & -.113 \\
2. Coll. teacher efficacy & 7.102 & 1.047 & -- & -- & -.125 \\
3. RTC site & -- & -- & -- & -- & -- \\
MJSE effort & 3.143 & .608 & -.035 & -.104 & -.075 \\
1. Teacher efficacy & 7.035 & .808 & -- & $.459^{* *}$ & -.113 \\
2. Coll. teacher efficacy & 7.102 & 1.047 & -- & -- & -.175 \\
3. RTC site & -- & -- & -- & -- & -- \\
\hline
\end{tabular}

${ }^{*} p \leq .055{ }^{* *} p<.01$.

Table 13 shows results from the series of simultaneous regression analyses. None of the models were statistically significant. The adjusted R-squared for the regression analyses were $\Delta R^{2}$ Talent $=-.009, \Delta R^{2}$ Context $=.012$, and $\Delta R^{2}$ Effort -.005 . These data 
demonstrate that virtually none of the variance in student academic efficacy was predictable from teacher efficacy, collective teacher efficacy, or RTC.

Table 13

Predicting Scores on MJSES Subscales Talent, Context, and Effort from Individual and Collective Teacher Efficacy.

\begin{tabular}{|c|c|c|c|c|c|c|}
\hline & \multicolumn{2}{|c|}{ Talent } & \multicolumn{2}{|c|}{ Context } & \multicolumn{2}{|c|}{ Effort } \\
\hline & \multicolumn{2}{|c|}{$\Delta R^{2}=-.009$} & \multicolumn{2}{|c|}{$\Delta R^{2}=.012$} & \multicolumn{2}{|c|}{$\Delta R^{2}=-.005$} \\
\hline & $\beta$ & $t$ & $\beta$ & $t$ & $\beta$ & $t$ \\
\hline Teacher efficacy & .004 & .041 & -.130 & -1.308 & .010 & .101 \\
\hline Collective teacher efficacy & .003 & -.028 & -.064 & -.643 & -.120 & -1.195 \\
\hline RTC site & .120 & 1.334 & -.107 & -1.205 & -.089 & -.988 \\
\hline
\end{tabular}




\section{CHAPTER 5}

\section{DISCUSSION AND CONCLUSIONS}

\section{Summary}

This dissertation explores the interaction of efficacy beliefs and teacher-student relationships within residential treatment centers (RTCs), particularly those specializing in adolescents with notable histories of abuse or neglect. RTCs are inherently challenging arenas of care for both students and their caregivers because of the myriad of emotional and behavioral problems presented by RTC residents. In over 40 years of RTC research one constant that has consistently been found to relate to positive resident outcomes is the development of supportive interpersonal relationships with RTC caregivers. Additionally, prior research tells us that specialized staff training, especially in regards to the cognitive and affective issues being faced by RTC residents, can significantly strengthen interpersonal relationships between residents and staff members (Frensch \& Cameron, 2002; Lyman \& Campbell, 1996; Knorth et al., 2007).

There are very few training and intervention programs designed to help direct care employees in RTCs work more effectively with their residents, with none geared specifically towards teachers. This challenge is especially amplified for teachers working with RTC residents because while approximately $50 \%$ of a resident's day is spent in a classroom environment, most residents present with serious behavioral disorders that their teachers had not been trained to address as a part of their academic teacher training (Libby et al., 2006; Edwards \& Chard, 2000). The role of RTC teachers is critical to this 
study because the two constructs which are investigated, efficacy beliefs and studentteacher relationships, are both linked to positive outcomes for teachers and students alike. For teachers, enhanced efficacy and positive relationships have been linked to higher levels of classroom engagement, an increased willingness to incorporate alternative teaching methods into the classroom, and increased achievement test scores on the part of their students (Yeo et al., 2008; Hamre \& Pianta, 2001; Croninger \& Lee, 2001). And with students, enhanced efficacy and positive relationships have been linked to higher levels of academic achievement, higher levels of reported bonding with teachers and school communities, and decreased deviant behaviors such as dropping out of school (Wentzel, 1998; Klem \& Connel, 2004; DiLalla, Marcus, \& Wright-Phillips, 2004). The lack of teacher-specific training in regards to RTC residents is a central aspect of this study because between pretest and posttest periods teachers received the Risking Connection ( $\mathrm{RC})$ training. The $\mathrm{RC}$ training is specifically designed to support RTC caregivers working with residents who have histories of emotional or physical trauma and neglect. It is important to note that the RC training method had never before been provided to academic teachers, and furthermore, the teachers in this study received a moderately abridged version of the training (10-12 hours over two days versus 16-18 hours over three) (S. Brown, personal communication, April 25, 2010).

Finally, three theoretical frameworks were intertwined to form the foundation for this study's research questions, and to provide structure for the interpretation and analysis of the study's results. First, attachment theory provides a platform for examining preexisting cognitive patterns which students and teachers alike bring into the teacherstudent relationship dynamic (Al-Yagon \& Mikulincer, 2004; Kennedy \& Kennedy, 
(2004). Additionally, attachment theory provides a structure for enhancing attachments when working with traumatized youth while conversely helping us to understand why some residents remain resistant to developing strong relationships with caregivers such as teachers. Second, social cognitive theory provides a foundation to better understand the broad concept of generalized self-efficacy and how self-efficacy can be filtered down to more specialized domains of efficacy such as teaching ability or academic success (Jinks \& Morgan, 1999; Bong, 1996). Efficacy beliefs are our perceived ability to control and manifest outcomes in our lives, stem from past experiences and how those experiences were reinforced by persons/experiences in our environment, and can be evaluated on both individual and collective levels (Bandura, 1997). Third, Pianta's application of general systems theory (GST) serves to help us further understand the complex role attachments and efficacy beliefs serve in the classroom (Rimm-Kaufman \& Chiu, 2007; Pianta, 1999). Pianta's use of GST reminds teachers to view their classrooms and students as members of a system that is better viewed from the sum of its perceptions, thoughts, and experiences rather than its singular parts. GST also reminds teachers that their primary strength in the classroom lies with their ability to regulate learning and social interactions, display consistent physical and emotional care, and model positive behavior and the academic task completion.

\section{Discussion and Conclusions: Research Question 1}

Research Question 1 investigated potential change in individual teacher efficacy on the part of RTC instructors as a result of the Risking Connection training. The question explicitly examined change in individual teacher efficacy within all of the teacher subjects, as well as between the Brooklawn and Maryhurst residential treatment 
centers. As anticipated in Chapter 3, low overall sample numbers required a fairly high critical $F$ to reach statistical significance, and as a result no statistically significant changes were observed for the within or between subject variables. Nevertheless, despite the challenge of power with this sample size, the interaction between pretest and posttest and the two programs neared significance, $\left(F_{(1,11)}=3.955, \mathrm{p}=.072\right)$. In addition, the interaction between RTCs, pretest, and posttest explained $18 \%$ of the variance in teacher efficacy. A closer examination of the means between the programs indicated that while pretest means were practically equal (Brooklawn $=7.04$, Maryhurst $=7.08$ ), at posttest means had increased at Maryhurst $(M=7.38)$ but decreased at Brooklawn $(M=6.53)$.

From the perspective of this study's design, the RC training appeared to have an impact upon teacher efficacy, but the opposing trends in change between Brooklawn and Maryhurst are difficult to explicate. One explanation could be found within the literature examining teacher efficacy, student gender, and student socioeconomic status (SES). Although by design this study did not investigate the SES of Maryhurst and Brooklawn students, the identification of most of the subjects as wards of the state suggests a high correlation with low SES status (Pierpont \& McGinty, 2004). Auwarter and Aruguete (2008) studied teacher perception, student gender, and SES and found an interaction effect between gender and SES. In their study they found that teachers rated low SES females more favorably than high SES females while conversely rating low SES boys less favorably than high SES boys. These results mirrored similar studies (see Childs $\&$ McKay, 2001) suggesting that low-SES boys may be especially vulnerable to negative teacher expectations. Thus, since Brooklawn serves only boys and Maryhurst serves only 
girls, the results of Research Question 1 could be related to student gender; however it is difficult to ascertain this for certain.

What this link fails to explain, however, is the negative trend demonstrated by Brooklawn (all males) teachers in relation to the positive trend of Maryhurst (all females) teachers from pretest to posttest. One hypothesis could be substantiated by social cognitive theory. If by default teachers' mastery or vicarious experiences were skewed to negative associations with boys in RTC settings; then one could posit that a training emphasizing the difficulty of working with this population could in essence provide a 'tipping point' that actually decreases individual perceptions of efficacy. For example, if an individual teacher's past mastery experiences were presented by the RC training as generally ineffective (e.g. authoritarian versus authoritative classroom management), perhaps the teachers felt a sense of inadequacy or hopelessness in regards to their ability to manage a classroom of boys in any other way? Along the same vein, if a teacher's past vicarious experience in observing mentors and peers interacting with students was challenged by the RC training (e.g. use of punishers versus reinforcers in classroom management), this too could serve to place their individual sense of efficacy into dissonance and doubt. In essence exasperating preexisting negative perceptions of the male students with whom they are working, and as a result contributing to an overall decline in individual teacher efficacy when working with a male population.

\section{Discussion and Conclusions: Research Question 2}

Research Question 2 investigated potential change in collective teacher efficacy on the part of RTC instructors as a result of the Risking Connection training. The question explicitly examined change in collective teacher efficacy within all of the 
teacher subjects, as well as between Brooklawn and Maryhurst. Despite the challenge of statistical power with this sample size, the within subjects effect for collective efficacy was found to be statistically significant $\left(F_{(1,11)}=2.01, \mathrm{p}=.05\right)$, accounting for $22 \%$ of the variance in collective teacher efficacy. What was especially surprising, however, was that the subject means from pretest to posttest declined from $M=7.22$ to $M=6.66$.

From the perspective of this study's design, the RC training appears to be associated with a negative effect on collective teacher efficacy. Within the literature there is a certain degree of precedent to explain these results. Anderson, Greene, and Lowen's (1988) study of individual and collective teacher efficacy presented results suggesting teachers have stronger perceptions of individual efficacy as compared to perceptions of the generalized efficacy of their peers. Unfortunately, Anderson, Greene, and Lowen's study is the only study of teacher efficacy which specifically explores individual efficacy in relation to collective efficacy with changes in efficacy over time. This gap in the literature will be further discussed at the conclusion of this chapter.

Furthermore, social cognitive theory provides a format to explain the potential for a specialized training such as Risking Connection to lower perceptions of collective efficacy. In one study of collective teacher efficacy, Goddard (2001) examined 99 different schools (with at least five teachers participating at each school) and found that mastery experiences explained approximately $66 \%$ of the variance between different programs in collective teacher efficacy. Therefore, since social cognitive theory demonstrates that social influence can shape collective efficacy beliefs, we can begin to make a link between overall past faculty performance and experience in relation to teachers' perceptions of collective efficacy. Thus, if for some reason an applied training 
such as RC serves to reinforce negative perceptions of past performance, then it makes sense to posit that collective efficacy beliefs can decline while individual beliefs continue to hold steady.

\section{Discussion and Conclusions: Research Question 3}

In Research Question 3, emphasis shifted to changes in students' perceptions of academic efficacy before and after their teachers received the RC training. In addressing Research Question 3, there were no significant within, between, or interaction effects among subjects or RTC programs. Also, no discernable effect sizes were attributed to changes in academic efficacy. However, one significant finding was associated with this question, a statistically significant quadratic contrast within the interaction between Brooklawn's and Maryhurst's slopes $\left(F_{(1,58)}=4.53, \mathrm{p}=.037\right)$. The essence of this finding is that while the differences between pretests and posttests were not significant, the slopes of each program's respective trends were.

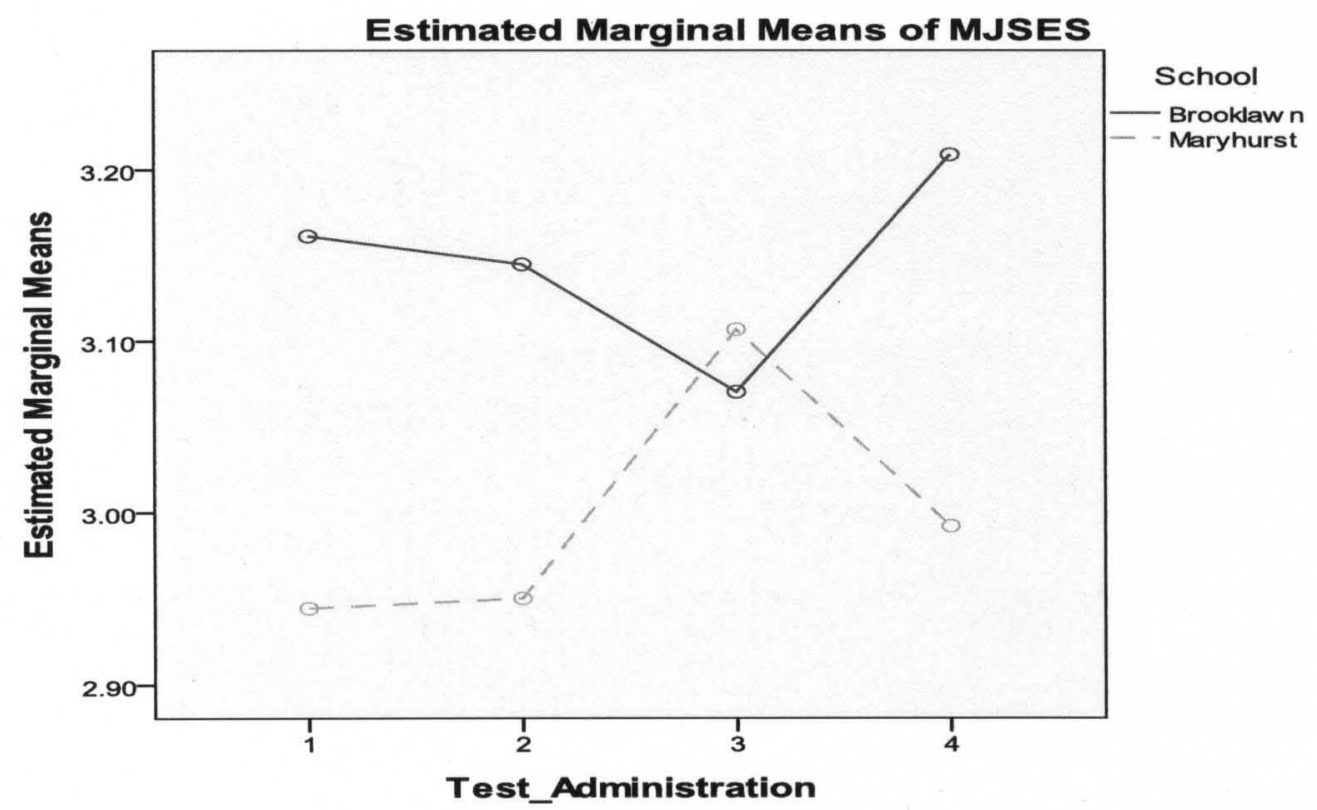

Figure 5. Trends in Academic Efficacy scores from pretest to posttest. 
Figure 5 provides a visual reference of this pattern. A caveat is necessary here because when the shifts in mean scores from administration one to four are closely examined, the variance within all of the respective means is fairly small. Consequently it seems prudent to interpret these results primarily from the perspective of informing future research. One potential avenue of exploration could lie in past studies indicating that girls tend to have higher levels of academic efficacy than boys. While there is a notable lack of research investigating gender differences in academic efficacy, studies do suggest that this difference can manifest as early as the fifth grade (Patrick, Hicks, \& Ryan,1997) and across diverse cultures (Pastorelli et al., 2001). Thus the results of Research Question 3 suggest that differences in academic efficacy between Brooklawn and Maryhurst may be related to gender rather than programmatic disparities.

\section{Discussion and Conclusions: Research Question 4}

Research Question 4 investigated change in students' perceptions regarding the strength of their relationship with first-period teachers. In addressing Research Question 4, there were no significant within, between, or interaction effects among subjects or RTC programs. Also, no discernable effect sizes were attributed to changes in academic efficacy. Student-teacher relationship ratings remained virtually the same throughout all four test administrations.

In respect to these particularly constant results, and given the fact that adolescence is a period usually marked by rapid changes in mood, affect, and the development of critical thinking skills (Baker \& Curtis, 2006; Walter \& Petr, 2007), it appears that this particular sample of students was unusually stable in their perceptions of 
student-teacher relationships. In this case, attachment and GST theories provide logical frameworks to interpret these results.

We know that insecure attachments are strongly related to negative emotional, interpersonal, and academic outcomes later in life, can become very difficult to alter once established, and that the attachment tendencies of students and teachers alike can impact the general system of a classroom (Kennedy \& Kennedy, 2004; Pianta, 2001; Westen et al., 2006). We also know that prevalence rates of insecure attachments can be as high as $77 \%$ in populations of children who have been victims of abuse or neglect (van Ijzendoorn et al., 1999). Thus it is possible that the majority of the subjects in this study suffered from such profound insecure attachments that they are psychologically incapable of developing or enhancing relationships with caregivers such as teachers. And as a result, their perspective of the teacher-student relationship would be most likely to remain stable or slowly decrease.

Additionally, since Pianta's application of GST to the classroom states that teachers can fall into behavioral interactions that mirror those of their students, and these interactions can negatively impact a teacher's ability to regulate learning and social interactions in the classroom system (Pianta, 1999), it seems reasonable to posit that a self-perpetuating cycle of negative or ambivalent interactions from teachers to students could be occurring. For example, past studies demonstrate that teachers differ in their ability to act as a secure foundation for students depending upon their own personal attachment tendencies (Kennedy \& Kennedy, 2004). Consequently, while a teacher with secure attachment tendencies will be more likely to respond to difficult students with support and sensitivity (Pianta \& Steinberg, 1992), teachers with dismissive tendencies 
may struggle to recognize their own lack of warmth or sensitivity, and teachers with preoccupied attachment tendencies may become easily distracted by a student's acting out behaviors at the expense of recognizing more important underlying issues (Kennedy \& Kennedy). As a result, a systems-based equilibrium could be occurring within the results produced by Research question 4 where the combined internal working models of teachers and students alike are resulting in neutral relationships with no significant growth or development.

\section{Discussion and Conclusions: Research Question 5}

Research Question 5 explored associations between individual and collective teacher efficacy and the quality of student-teacher relationships in RTCs. Unlike the previous Research Questions, the focus of Research Question 5 was to assess potential associations prior to the $\mathrm{RC}$ training. It was theorized that if the $\mathrm{RC}$ training did in fact have an impact upon teacher efficacy and/or the student-teacher relationship then any obtained results would not be generalizable to broader RTC populations. A simultaneous regression analysis using teacher and collective teacher efficacy as predictors of the student-teacher relationship was found to be statistically significant $\left(F_{(2,126)}=6.792, \mathrm{p}<\right.$ .001 ) with approximately $12 \%$ of the variance in teacher/student relationship being predictable from individual and collective teacher efficacy.

While this is an interesting stand-alone result, closer examination of the correlations between these three variables produced contradictory trends (Figure 6). Consistent with the existing efficacy literature (Fives \& Looney, 2009; Lewis, 2009; Skaalvik \& Skaalvik, 2007), teacher efficacy and collective efficacy have a moderate positive correlation with each other. But when the correlations of individual and 
collective teacher efficacy are examined, two opposing relationships appeared. In two statistically significant correlations, individual teacher efficacy was negatively associated with student-teacher relationships while collective teacher efficacy was positively associated with student-teacher relationships.

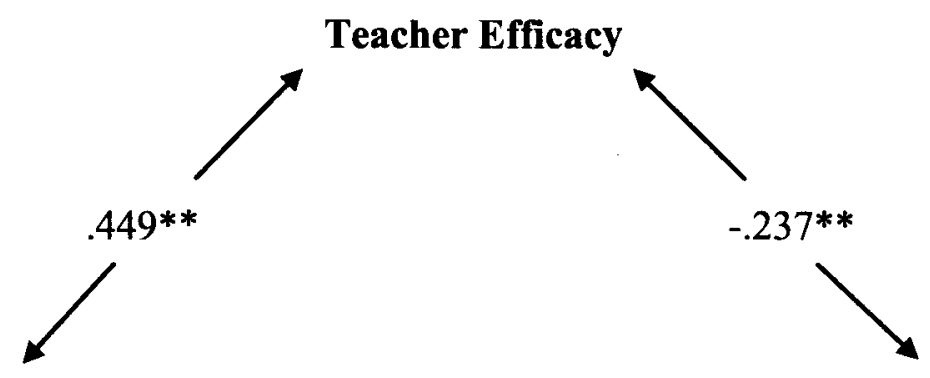

Collective Teacher Efficacy $.141^{*}$

Student-Teacher

\section{Relationship}

Figure 6. Trends in Correlations between Teacher Efficacy Beliefs and Student Perception of the Teacher-Student Relationship. ${ }^{*}=p<.05 .{ }^{* *}=p<.01$.

The negative correlation between teacher efficacy and student-teacher relationships is notably inconsistent with the teacher efficacy literature. The vast body of teacher efficacy literature consistently outlines positive correlations between teacher efficacy and enhanced social and academic performance by their students. Thus it seems likely that something about the RTC environment is contributing to this particular result. Again, attachment theory and GST provide frameworks to postulate as to the source of these findings.

From the attachment perspective, as with Research Question 4, one explanation is that RTC students' particularly high potential for insecure attachments is impacting the student-teacher relationship dynamic. And as a result, traditionally positive behaviors demonstrated by high-efficacy teachers (e.g., structured classrooms, high expectations, 
and enhanced enthusiasm) may have a negative impact on students who are psychologically intimidated or threatened by their actions. Since we know that adolescents with insecure attachments use less effective strategies in stressful situations, struggle to regulate negative cognitions, and display negative externalizing behaviors (Kennedy \& Kennedy, 2004), it is reasonable to posit that traditionally efficacious teacher behaviors are being perceived as threatening or confusing to the sensitive internal working models of their students. As an end result, a disconnect may be occurring between students and their teachers where neutral growth student-teacher relationships become the byproduct.

Conversely, from the GST perspective, it is also possible that teachers are bringing something into the classroom system which has a negative impact on the relationship-based perceptions of their students. GST reminds us that while teachers have the ability to regulate a student's learning and social interactions within the context of the holistic classroom community, the sum of the perceptions, thoughts, and experiences of their collective students is more influential than any one individual (Pianta, 2001; RimmKaufman \& Chiu, 2007). Thus, if complex maladaptive behaviors are being exhibited by a high percentage of a classroom's students it seems possible that a teacher could become distracted or allow their own attachment tendencies to negatively impact the classroom system. As a result, a teacher's ability to foster strong relationships with their students could be negatively impacted by their teacher-student interactions and interventions. Which again, in relation to their students' limited emotional capacity to engage in positive relationship growth, is serving to neutralize relationship development. 
The positive correlation between collective teacher efficacy and student-teacher relationships is consistent with the literature and could provide insight into the overall decrease in collective efficacy scores that were explored in Research Question 2. For example, in a multi-school comparison study, Goddard (2001) found that group means of collective teacher efficacy were more predictive of student success than consensus of collective efficacy. In essence, this study's results are a measure of consensus and a measure of outcome. Thus while the teacher's consensus of collective efficacy did decrease, a significant positive correlation was found between collective efficacy and student-teacher relationships, particularly in contrast to the negative correlation demonstrated between individual teacher-efficacy and student-teacher relationships. While the strength of all of these correlations where not particularly strong, they suggest that future interventions with teachers in RTC settings should examine enhancing collective efficacy as a potentially more beneficial influence when attempting to enhance student-teacher relationships.

\section{Discussion and Conclusions: Research Question 6}

Research Question 6 explored associations between individual and collective teacher efficacy and the three subscales of the MJSES (talent, context, and effort). As with Research Question 5, the objective of this question was to assess potential associations prior to the $\mathrm{RC}$ training. Three different simultaneous regression analyses using teacher and collective teacher efficacy as predictors of MJSES talent, MJSES context, and MJSES effort were conducted with all three analyses producing insignificant results. In addition, post hoc assessment of effect size showed virtually none of the variance in the MJSES efficacy subscales to be related to individual or collective teacher 
efficacy. Within this study no relationship existed between teacher and student efficacy prior to the $\mathrm{RC}$ training, a result inconsistent with existing literature.

Congruent with findings from Research Question 3, these results are not surprising. Since no shift in student efficacy on the global MJSES measure occurred, it makes sense that no discernable relationship with shifts in teacher efficacy would occur. It should be noted that the results of Research Question 6 highlight one of the most notable limitations of this study which is the lack of a comparison group. Without a comparison group it is impossible to examine whether the absence of a relationship between teacher and student efficacy is reflective of a trend unique to the sample population or RTC populations in general.

\section{Limitations}

This study had several limitations that should be identified. First, it must be stressed that this study was quasi-experimental in design. Therefore any implications of change before and after the Risking Connection training cannot be definitively linked to Risking Connection. The potential for confounding variables such as teacher burnout, shifts in administration policy, and teaching within same-gender classrooms could not be controlled within this study's design. Second, this study would have benefitted from the participation of a non-clinical comparison group. Without a comparison group consisting of teachers/students in a traditional school setting it is difficult to ascertain what specific trends were unique to RTC populations. Third, there was a notable time limitation within this study, especially in regards to the posttest evaluations of change from the students' perspective. Insecure attachment styles, and the resulting cognitions driven by maladaptive schemas within a person's IWM, become very deep-rooted and difficult to 
change as an individual ages (Main \& Solomon, 1990; Kennedy \& Kennedy, 2004). As a result, notable change in the ability of RTC students to develop relationships or enhance efficacy beliefs appears unlikely in a two and one-half month period. And fourth, the sample size in regards to the teachers was small and fairly homogenous. Only 13 teachers participated in the study with the majority being Caucasian females. Larger numbers of teachers, ideally with more diverse numbers of men and minorities, would have enhanced the results of the teacher data significantly.

\section{Implications for Practice}

Despite the limitations of this study, findings point to implications for enhancement of specialized training programs focused towards teachers in RTC settings. First, one emphasis of training programs specific to teachers in RTC settings should be on the unique role gender appears to play in the development of teacher and student efficacy. The results of this study suggest that individual perceptions of teacher efficacy trended downward with male students and upward with female students. This could be linked to prior studies demonstrating that teachers working with low SES populations tend to have negative expectations of their male students and positive expectations of their female students (Auwarter \& Aruguete, 2008; Childs \& McKay, 2001). As a result, teachers should be made aware of this tendency and encouraged to explore challenges unique to their respective institutions (e.g. working in an institution with only male or female students).

Second, leaders of training programs specific to teachers in RTC settings should consider emphasizing collective teacher efficacy rather than individual teacher efficacy. The results of this study suggest that collective teacher efficacy beliefs were positively 
correlated with teacher-student relationships while conversely, individual teacher efficacy beliefs were negatively correlated with student-teacher relationships. These results are consistent with prior studies suggesting that collective teacher efficacy is more powerfully associated with positive student outcomes than individual teacher efficacy (Goddard, 2001; Goddard, Hoy, \& Hoy, 2004). A key area where RTC specific teacher training programs could foster collective teacher efficacy lies in training teachers to collaborate in classroom planning while encouraging peer (e.g. teacher to teacher) observation, and evaluation. Findings reported here suggest that, when collective teacher efficacy is enhanced, an RTC's collective teaching staff develops positive normative pressure to succeed while maintaining a supportive and collegial atmosphere.

Finally, the challenge of integrating the enhancement of student academic efficacy with positive teacher-student relationships should be explored in training programs specific to teachers in RTC settings. For example, while this study did produce results indicating change related to the Risking Connection training within studentteacher relationships, no changes occurred in regards to student academic efficacy beliefs. The fact that this study showed no significant relationships between individual or collective teacher efficacy and student academic efficacy was inconsistent with past studies which have shown strong relationships between similar variables (Goddard et al., 2004; Jinks \& Morgan, 1999; Midgley et al., 1989; Tschannen-Moran \& Barr, 2004). This contradiction suggests that traditional pedagogical techniques and behavioral interventions teachers have developed through their education and career development (i.e. didactic-based teaching methods and punishment based behavioral interventions) 
might be contributing to a lack of efficacy enhancement on the part of individual students.

\section{Implications for Future Research}

While this study addresses notable gaps in the literature regarding the development of teacher efficacy, student efficacy, and positive teacher-student relationships in RTC settings, critical areas of inquiry remain. First, findings from this study demonstrated that a specialized training program appears to have had an impact upon changes in individual and collective teacher efficacy. The results of this change, however, were inconsistent. As a result, future research should investigate the structure and emphases of specialized trainings geared specifically toward teachers working with RTC students, especially those whose students have significant attachment challenges.

An additional area of exploration for research should examine varying trends in teachers' perceptions of male versus female students. This is especially pertinent in regards to prior studies that have explored the role of gender-influenced teacher perceptions of both typical and at-risk student populations. For example, within typical student populations girls are more likely to be perceived by teachers as having close student-teacher relationships while boys are more likely to be perceived by teachers as having more conflictual relationships (Jerome, Hamre, \& Pianta, R. 2009). Additionally, when examining at-risk students, teachers working with low SES populations tend to have negative academic and behavioral expectations of their male students while having more positive academic and behavioral expectations of their female students (Auwarter \& Aruguete, 2008; Childs \& McKay, 2001). Thus future researchers should consider 
designing training programs specific to RTC teachers that address these issues by helping teachers grasp this discrepancy.

Another area of future research in specialized training could investigate change in individual and collective teacher efficacy over the course of the academic year. If changes in teachers' perceptions of efficacy decrease as the year progresses, interventions could be designed accordingly. Finally, future researchers will want to investigate the impact of teachers' pre-existing individual and collective efficacy perceptions upon the effectiveness of specialized training outcomes. If future researchers can identify what teacher efficacy beliefs are complementary and/or in conflict with specialized training programs, compensatory training models could be developed.

This study has also identified areas of future research regarding individual teachers and students. Concerning academic efficacy, there is a noticeable lack of information available differentiating the perception and enhancement of efficacy between males and females. Questions investigating whether different genders process, utilize, and develop efficacy beliefs remain to be answered. Further studies should also strive to better integrate teacher and student self-report instruments. The vast majority of literature surrounding teacher-student relationships and academic efficacy use only teacher-report (e.g. teacher efficacy scales and teacher-rating of perceived teacher-student relationship quality) or only student-report (e.g. efficacy self-reports and student ratings of perceived student-teacher relationships). Finally, future work should include comparisons between RTC students and parallel groups of traditional students. When the dearth of applied research specific to RTC student populations is considered, the level of generalizability within the literature (i.e. teacher-student relationship and academic/teacher efficacy 
studies with more typical student populations) remains unclear. Comparison studies would help elucidate the differences and similarities between traditional and RTC populations and enhance the development of academic and behavioral interventions specific to RTCs. 


\section{REFERENCES}

Abbott, R., \& O'Donnell, J. (1998). Changing teaching practices to promote achievement and bonding to school. American Journal of Orthopsychiatry, 68(4), 542.

Ainsworth, M., Blehar, M., Waters, E., \& Wall, S. (1978). Patterns of attachment: A psychological study of the Strange Situation. Hillsdale, NJ: Erlbaum.

Alderman, M. (1990). Motivation for at-risk students. Educational Leadership, 48(1), 2730.

Allen, C. (2003). Making sense of context: An analysis of mesosystemic influences impacting first- and second-year beginning teachers' sense of efficacy. Dissertation Abstracts International Section A, 64, 1967.

Allinder, R. (1994). The relationship between efficacy and the instructional practices of special education teachers and consultants. Teacher Education and Special Education, 17(2), 86-95.

Al-Yagon, M., \& Mikulincer, M. (2004). Socioemotional and academic adjustment among children with learning disorders: The mediational role of attachment-based factors. Journal of Special Education, 38(2), 111-123.

Anderson, R., Greene, M., \& Loewen, P. (1988). Relationships among teachers' and students' thinking skills, sense of efficacy, and student achievement. Alberta Journal of Educational Research, 34(2), 148-165.

Auwarter, A., \& Aruguete, M. (2008). Effects of student gender and socioeconomic status on teacher perceptions. Journal of Educational Research, 101(4), 242-246. 
Baker, A., \& Curtis, P. (2006). Prior placements of youth admitted to therapeutic foster care and residential treatment centers: The Odyssey Project population. Child \& Adolescent Social Work Journal, 23(1), 38-60.

Bates, B., English, D., \& Kouidou-Giles, S. (1997). Residential treatment and its alternatives: A review of the literature. Child \& Youth Care Forum, 26(1), 7-51.

Bandura, A. (1986). Social foundations of thought and action: A social cognitive theory. Englewood Cliffs, NJ US: Prentice-Hall.

Bandura, A. (1997). Self-efficacy: The exercise of control. New York: Freeman

Bandura, A. (1989). Human agency in social cognitive theory. American Psychologist, $77,122-147$.

Bandura, A., \& Cervone, D. (1983). Self-evaluative and self-efficacy mechanisms governing the motivational effects of goal systems. Journal of Personality and Social Psychology, 45(5), 1017-1028.

Baker, J. (2006). Contributions of teacher-child relationships to positive school adjustment during elementary school. Journal of School Psychology, 44, 211-229.

Baker, A., \& Curtis, P. (2006). Prior placements of youth admitted to therapeutic foster care and residential treatment centers: The Odyssey Project population. Child \& Adolescent Social Work Journal, 23(1), 38-60.

Bergin, C., \& Bergin, D. (2009). Attachment in the Classroom. Educational Psychology Review, 21(2), 141-170.

Bong, M. (1996). Perceived similarity among tasks and generalizability of academic selfefficacy. (ERIC Document Reproduction Service No. ED411258). Retrieved September 20, 2009, from ERIC database. 
Bong, M. (1997). Generality of academic self-efficacy judgments: Evidence of hierarchical relations. Journal of Educational Psychology, 89(4), 696-709.

Bong, M., \& Skaalvik, E. (2003). Academic self-concept and self-efficacy: How different are they really? Educational Psychology Review, 15(1), 1-40.

Bowlby, J. (1969). Attachment (Vol. 1). New York: Basic Books.

Campbell, J. (1996). A comparison of teacher efficacy for pre and in-service teachers in Scotland and America. Education, 117, 2-11.

Cavell, T., Elledge, L., Malcolm, K., Faith, M., \& Hughes, J. (2009). Relationship quality and the mentoring of aggressive, high-risk children. Journal of Clinical Child \& Adolescent Psychology, 38(2), 185-198.

Childs, G., \& McKay, M. (2001). Boys starting school disadvantaged: Implications from teachers' ratings of behavior and achievement in the first two years. British Journal of Educational Psychology, 71, 303-314.

Choi, N. (2005). Self-efficacy and self-concept as predictors of college students' academic performance. Psychology in the Schools, 42(2), 197-205.

Cohen, J. (1988). Statistical power for the behavioral sciences (2nd ed.). Hillsdale, NJ: Erlbaum.

Comaty, J., Stasio, M., \& Advokat, C. (2001). Analysis of outcome variables of a token economy system in a state psychiatric hospital: A program evaluation. Research in Developmental Disabilities, 22, 233-253.

Connor, D., McIntyre, E., Miller, K., Brown, C., Bluestone, H., Daunais, D., et al. (2003). Staff retention and turnover in a residential treatment center. Residential Treatment for Children \& Youth, 20, 43-52. 
Connor, D., \& McLaughlin, T. (2005). A naturalistic study of medication reduction in a residential treatment setting. Journal of Child and Adolescent Psychopharmacology, 15, 302-310.

Crittenden, P., \& Dallos, R. (2009). All in the family: Integrating attachment and family systems theories. Clinical Child Psychology \& Psychiatry, 14, 389-409.

Croninger, R., \& Lee, V. (2001). Social capital and dropping out of high school: Benefits to at-risk students of teachers' support and guidance. Teachers College Record, $103,548-571$.

Curry, J. (2004). Future directions in residential treatment outcome research. Child and Adolescent Psychiatric Clinics of North America, 13(2), 429-440.

Decker, D., Dona, D., \& Christenson, S. (2007). Behaviorally at-risk African American students: The importance of student-teacher relationships for student outcomes. Journal of School Psychology, 45, 83-109.

de la Torre Cruz, M., \& Casanova Arias, P. (2007). Comparative analysis of expectancies of efficacy in in-service and prospective teachers. Teaching \& Teacher Education, 23(5), 641-652.

DiLalla, L., Marcus, J., \& Wright-Phillips, M. (2004). Longitudinal effects of preschool behavioral styles on early adolescent school performance. Journal of School Psychology, 42, 385-401.

Edwards, L., \& Chard, D. (2000). Curriculum reform in a residential treatment program: Establishing high academic expectations for students with emotional and behavioral disorders. Behavioral Disorders, 25(3), 259-263.

Emmer, E., \& Hickman, J. (1991). Teacher efficacy in classroom management and discipline. Educational and Psychological Measurement, 51, 755-765. 
Epstein, M. H., Kinder, D., \& Bursuck, B. (1989). The academic status of adolescents with behavioral disorders. Behavioral Disorders, 14, 157-165.

Erdman, P., \& Caffery, T. (2000). An interview with Robert Marvin: Linking systems and attachment theory. Family Journal, 8(3), 309-316.

Faul, F., Erdfelder, E., Lang, A.-G., \& Buchner, A. (2007). G*Power 3: A flexible statistical power analysis program for the social, behavioral, and biomedical sciences. Behavior Research Methods, 39, 175-191.

Finney, S. \& Schraw, G. (2003). Self-efficacy beliefs in college statistics courses. Contemporary Educational Psychology, 28, 161-186.

Fives, H., \& Looney, L. (2009). College instructors' sense of teaching and collective efficacy. International Journal of Teaching and Learning in Higher Education, 20(2), 182-191.

Foltz, R. (2004). The Efficacy of Residential Treatment: An Overview of the Evidence. Residential Treatment for Children \& Youth, 22(2), 1-19.

Frensch, K., \& Cameron, G. (2002). Treatment of choice or a last resort? A review of residential mental health placements for children and youth. Child \& Youth Care Forum, 31(5), 307-339.

Gibson, S., \& Dembo, M. (1984). Teacher efficacy: A construct validation. Journal of Educational Psychology, 76(4), 569-82.

Giller, E., Vermilyea, E., \& Steele, T. (2006). Risking Connection: Helping agencies embrace relational work with trauma survivors. Journal of Psychological Trauma, $5,65-82$.

Goddard, R. (2001). Collective efficacy: A neglected construct in the study of schools and student achievement. Journal of Educational Psychology, 93(3), 467-476. 
Goddard, R., Hoy, W., \& Hoy, A. (2000). Collective teacher efficacy: Its meaning, measure, and effect on student achievement. American Education Research Journal, 37, 479-507.

Goddard, R., Hoy, W., \& Hoy, A. (2004). Collective efficacy beliefs: Theoretical developments, empirical evidence, and future directions. Educational Researcher, 33(3), 3-13.

Goodenow, C. (1993). Classroom belonging among early adolescent students: Relationships to motivation and achievement. The Journal of Early Adolescence, 13(1), 21-43.

Greenberg, M., Speltz, M., Deklyen, M., \& Endriga, M. (1991). Attachment security in preschoolers with and without externalizing behavior problems: A replication. Development and Psychopathology, 3, 413-430.

Greenberg, M., Weissberg, R., O'Brien, M., Zins, J., Fredericks, L., Resnik, H., et al. (2003). Enhancing School-Based Prevention and Youth Development Through Coordinated Social, Emotional, and Academic Learning. American Psychologist, $58,466-474$

Gregory, A. \& Weinstein, S. R. (in press). A window on the discipline gap: Defiance or cooperation in the high school classroom. Journal of School Psychology.

Guskey, T. (1988). Teacher efficacy, self-concept, and attitudes toward the implementation of instructional innovation. Teaching and Teacher Education, 4, 63-69.

Hamilton, N. (1988). Self and others: Object relations theory in practice. Northvale, NJ: Jason Aronson Inc. 
Hamman, D., \& Hendricks, C. (2005). The role of the generations in identity formation: Erikson speaks to teachers of adolescents. Clearing House: A Journal of Educational Strategies, Issues and Ideas, 79, 72-75.

Hamre, B., \& Pianta, R. (2001). Early teacher-child relationships and the trajectory of children's school outcomes through eighth grade. Child Development, 72(2), 625.

Herrero, J., Estévez, E., \& Musitu, G. (2006). The relationships of adolescent schoolrelated deviant behaviour [sic] and victimization with psychological distress: Testing a general model of the mediational role of parents and teachers across groups of gender and age. Journal of Adolescence, 29(5), 671-690.

Howes, C. (1999). Attachment relationships in the context of multiple caregivers. In J. Cassidy and P. Shaver (Eds.), Handbook of attachment: Theory, research, and clinical applications (pp. 671-687). New York, NY: Guilford Press.

Individuals with disabilities act amendments of 1997. (2009). Retrieved online September, 25, 2009, from http://www.ed.gov/legislation/FedRegister/finrule/1999-2/062499a.pdf.

Jerome, E., Hamre, B., \& Pianta, R. (2009). Teacher-child relationships from kindergarten to sixth grade: Early childhood predictors of teacher-perceived conflict and closeness. Social Development, 18(4), 915-945

Jinks, J., \& Morgan, V. (1999). Children's perceived academic self-efficacy: An inventory scale. Clearing House, 72(4), 224.

Lewis, S. (2009). The contribution of elements of teacher collaboration to individual and collective teacher efficacy. Dissertation Abstracts International Section A, 70, Retrieved April 8, 2010 from PsycINFO database. 
Kennedy, J., \& Kennedy, C. (2004). Attachment theory: Implications for school psychology. Psychology in the Schools, 41, 247-259.

Keppel, G., \& Wickens, T. (2004). Design and analysis: A researcher's handbook (4 ${ }^{\text {th }}$ ed.). Upper Saddle River, NJ: Pearson Prentice Hall.

Klem, A., \& Connell, J. (2004). Relationships matter: Linking teacher support to student engagement and achievement. Journal of School Health, 74(7), 262-273.

Knorth, E., Harder, A., Zandberg, T., \& Kendrick, A. (2008). Under one roof: A review and selective meta-analysis on the outcomes of residential child and youth care. Children and Youth Services Review, 30(2), 123-140.

Lane, K., Wehby, J., \& Barton-Arwood, S. (2005). Students with and at risk for emotional and behavioral disorders: Meeting their social and academic needs. Preventing School Failure, 49(2), 6-9.

Lane, K., Barton-Arwood, S., Nelson, J., \& Wehby, J. (2008). Academic performance of students with emotional and behavioral disorders Served in a self-contained setting. Journal of Behavioral Education, 17(1), 43-62.

Lent, R., Brown, S., \& Gore, P. (1997). Discriminate and predictive validity of academic self-concept, academic self-efficacy, and mathematics-specific self-efficacy. Journal of Counseling Psychology, 44, 307-315.

Leone, P., Zaremba, B., Chapin, M., \& Iseli, C. (1995). Understanding the overrepresentation of youths with disabilities in juvenile detention. District of Columbia Law Review, 3, 389-401.

Lewis, W. (1982). Ecological Factors in Successful Residential Treatment. Behavioral Disorders, 7, 149-56. 
Libby, A.M., Coen, A.S., Price, D.A., Silverman, K., Orton, H.D. (2005). Inside the black box: What constitutes a day in a residential treatment centre? International Journal of Social Welfare, 14, 176-183.

Lieberman, R. (2004). Future directions in residential treatment, Child and Adolescent Psychiatry Clinics of North America, 13, 279-294.

Lyman, R., \& Campbell, N. (1996). Treating children and adolescents in residential and inpatient settings. Thousand Oaks, CA US: Sage Publications, Inc.

Lyons-Ruth, K., Esterbrooks, M., \& Cibelli, C. (1997). Infant attachment strategies, infant mental lag, and maternal depressive symptoms: Predictors of internalizing and externalizing problems at age 7. Developmental Psychology, 33, 681-692.

Main, M., \& Solomon, J. (1990). Procedures for identifying infants as disorganized/disoriented during the Ainsworth Strange Situation. In D. Cicchetti and E. Cummings (Eds.), Attachment in the preschool years: Theory, research, and intervention (pp. 121-160). Chicago, IL: University of Chicago Press.

Maine, M., \& Solomon, J., (1986). Discovery of a new, insecure-disorganizeddisoriented attachment pattern. In T.B. Brazelton \& M. Yogmán (Eds.), Affective development in infancy (pp. 95-124). Norwood, NJ: Ablex.

Margolis, H., \& McCabe, P. (2004). Self-Efficacy: A key to improving the motivation of struggling learners. Clearing House, 77, 241-249.

Mathur, S., Kavale, K., Quinn, M., Forness, S., \& Rutherford, R. (1998). Social skills interventions with students with emotional and behavioral problems: A quantitative synthesis of single-subject research. Behavioral Disorders, 23, 193201. 
McCurdy, B., \& McIntyre, E. (2004). ‘And what about residential...?’ Reconceptualizing residential treatment as a stop-gap service for youth with emotional and behavioral disorders. Behavioral Interventions, 19, 137-158.

McEvoy, A., \& Welker, R. (2000). Antisocial behavior, academic behavior, and school climate: A critical review. Journal of Emotional and Behavioral Disorders, 8, $130-140$.

McMackin, R., Tansi, R., \& Hartwell, S. (2005). Proficiency in basic educational skills as related to program outcome and escape risk among juvenile offenders in residential treatment. Journal of Offender Rehabilitation, 42(3), 57-74.

Meehan, B., Hughes, J., \& Cavell, T. (2003). Teacher-student relationships as compensatory resources for aggressive children. Child Development, 74(4), 1145 1157.

Myers, S., \& Pianta, R. (2008). Developmental commentary: Individual and contextual influences on student-teacher relationships and children's early problem behaviors. Journal of Clinical Child and Adolescent Psychology, 37, 600-608.

Midgley, C., Feldlaufer, H., \& Eccles, J. (1989). Change in teacher efficacy and student self- and task-related beliefs in mathematics during the transition to junior high school. Journal of Educational Psychology, 81(2), 247-258.

Moore, W., \& Esselman, M. (1992). Teacher efficacy, empowerment, and a focused instructional climate: Does student achievement benefit? Retrieved online October 12, 2009, from ERIC online publications at http://www.eric.ed.gov/ERICDocs/data/ericdocs2sq//content_storage_01/0000019 b/80/12/df/39.pdf 
Ormond, J. (2000). Education psychology: Developing learners. $3^{\text {rd }}$ ed. Upper Saddle River, NJ: Prentice Hall.

Pajares, F. (2003). Self-efficacy beliefs, motivation, and achievement in writing: A review of the literature. Reading \& Writing Quarterly, 19, 139-164.

Pajares, F., \& Schunk, D. (2001). Self-beliefs and school success: Self-efficacy, selfconcept, and school achievement. In R. Ridling \& S. Rayner (Eds.), Perception (pp. 239-265). Westport, CT: Ablex Publishing.

Pastorelli, C., Caprara, G., Barbaranelli, C., Rola, J., Rozsa, S., \& Bandura, A. (2001). The structure of children's perceived self-efficacy: A cross-national study. European Journal of Psychological Assessment, 17, 87-97.

Patrick, H., Hicks, L., \& Ryan, A. (1997). Relations of perceived social efficacy and social goal pursuit to self-efficacy for academic work. The Journal of Early Adolescence, 17(2), 109-128.

Pearlman, L. (1998). Trauma and the self: A theoretical and clinical perspective. Journal of Emotional Abuse, 1, 7-25.

Pedhazur, E. (1997). Multiple regression in behavioral research: Explanation and prediction $\left(3^{\text {rd }}\right.$ ed.). New York: Thomson Learning, Inc.

Pianta, R. (2006). Schools, schooling, and developmental psychopathology. In D. Cicchetti and D. Cohen (Eds.), Developmental psychopathology, Vol 1: Theory and method (2nd ed.) (pp. 494-529). Hoboken, NJ: John Wiley \& Sons Inc.

Pianta, R. (2001). Implications of a developmental systems model for preventing and treating behavioral disturbances in children and adolescents. In J. Hughes, A. La Greca, \& J. Conoley (Eds.) Handbook of psychological services for children and adolescents (pp. 23-41). New York, NY US: Oxford University Press. 
Pianta, R. (1999). Enhancing relationships between children and teachers. Washington, DC: American Psychological Association.

Pianta, R. \& Allen J. (2009). About MTP secondary. Retrieved online September October, 11, 2009, from http://www.mtpsecondary.net/about public/index.php.

Pianta, R., \& Steinberg, M. (1992). Teacher-child relationships and the process of adjusting to school. In R. Pianta (Ed.), Beyond the parent: The role of other adults in children's lives (pp. 61-80). San Francisco, CA: Jossey-Bass.

Pierpont, J., \& McGinty, K. (2004). Using Family-Oriented Treatment to Improve Placement Outcomes for Children and Youth in Residential Treatment. Journal of Human Behavior in the Social Environment, 9, 147-163.

Reid, R., Gonzalez, J., Nordness, P., Trout, A., \& Epstein, M. (2004). A meta-analysis of the academic status of students with emotional/behavioral disturbance. Journal of Special Education, 38(3), 130-143.

Resnick, M., \& Bearman, P. (1997). Protecting adolescents from harm. Journal of the American Medical Association, 278, 823-832.

Rimm-Kaufman, S., \& Chiu, Y. (2007). Promoting social and academic competence in the classroom: An intervention study examining the contribution of the Responsive Classroom approach. Psychology in the Schools, 44, 397-413.

Roeser, R., Eccles, J., \& Sameroff, A. (1998). Academic and emotional functioning in early adolescence: Longitudinal relations, patterns, and prediction by experience in middle school. Development and Psychopathology, 10, 321-352.

Roeser, R., Midgley, C., \& Urdan, T. (1996). Perceptions of the school psychological environment and early adolescents' psychological and behavioral functioning in 
school: The mediating role of goals and belonging. Journal of Educational Psychology, 88, 408-422.

Ross, J. (1992). Teacher efficacy and the effects of coaching on student achievement. Canadian Journal of Education, 17(1), 51-65.

Rudasill, K. M., Reio, T., Kosine, N., \& Taylor, J. (2009). Temperament and student-teacher relationship quality predict risky behavior among young adolescents. Manuscript under review with Journal of Adolescence.

Saakvitne, K., Tennen, H., \& Affleck, G. (1999) Exploring thriving in the context of clinical trauma theory: Constructivist Self Development Theory. Journal of Social Issues, 54, 279-299.

Schunk, D. (1984). Self-efficacy perspective on achievement behavior. Educational Psychologist, 19(1), 48-58.

Schunk, D. (2001). Social cognitive theory and self-regulated learning. In B. Zimmerman \& D. Schunk (Eds.), Self-regulated learning and academic achievement: Theoretical perspectives (2nd ed.) (pp. 125-151). Mahwah, NJ: Lawrence Erlbaum Associates Publishers.

Schunk, D., \& Hanson, A. (1989). Influence of peer-model attributes on children's beliefs and learning. Journal of Educational Psychology, 81(3), 431-434.

Soodak, L., \& Podell, D. (1993). Teacher efficacy and student problem as factors in special education referral. Journal of Special Education, 27(1), 66-81.

Schunk, D., \& Swartz, C. (1993). Goals and progress feedback: Effects on self-efficacy and writing achievement. Contemporary Educational Psychology, 18, 337-354. 
Schunk, D., \& Zimmerman, B. (2007). Influencing children's self-efficacy and selfregulation of reading and writing through modeling. Reading \& Writing Quarterly: Overcoming Learning Difficulties, 23, 7-25.

Skaalvik, E., \& Skaalvik, S. (2007). Dimensions of teacher self-efficacy and relations with strain factors, perceived collective teacher efficacy, and teacher burnout. Journal of Educational Psychology, 99(3), 611-625.

Skinner, E. A., \& Belmont, M. J. (1993). Motivation in the classroom: Reciprocal effects of teacher behavior and student engagement across the school year. Journal of Educational Psychology, 85, 571-581.

Spronck, W., \& Compernolle, T. (1997). Systems theory and family therapy: From a critique on systems theory to a theory on system change. Contemporary Family Therapy: An International Journal, 19(2), 147-176.

Stein, M., \& Wang, M. (1988). Teacher development and school improvement: The process of teacher change. Teaching and Teacher Education, 4(2), 171-87.

Tschannen-Moran, M. (2009). The collective teacher beliefs scale. Survey instruments to help you in your investigations of schools. Retrieved online October 11, 2009, from http://mxtsch.people.wm.edu/ResearchTools/CTB_OMR.pdf.

Tschannen-Moran, M. (2009). Teacher sense of efficacy scale. Survey instruments to help you in your investigations of schools. Retrieved online October 11, 2009, from http://mxtsch.people.wm.edu/ResearchTools/TSES_Short_OMR.pdf

Tschannen-Moran, M., \& Barr, M. (2004). Fostering student learning: The relationship of collective teacher efficacy and student achievement. Leadership \& Policy in Schools, 3(3), 189-209. 
Tschannen-Moran, M., \& Woolfolk-Hoy, A. (2001). Teacher efficacy: Capturing an elusive construct. Teaching and Teacher Education, 17, 783-805.

Taylor, D., \& Alpert, S. (1973). Continuity and support following residential treatment. Oxford England: Child Welfare League of America.

U.S. Department of Education. (2009). Twenty-third annual report to Congress on the implementation of the Individuals with Disabilities Education Act. Washington, DC: Retrieved online September 30, 2009, from http://www.ed.gov/about/reports/annual/osep/2000/preface.pdf.

U.S. Department of Health and Human Services, Substance Abuse and Mental Health Services Administration. (2009). Sources and qualifications of data from the survey of mental health organizations. Retrieved online September 19, 2009, from http://mentalhealth.samhsa.gov/publications/allpubs/SMA01-3537/appendixa.asp.

Valiente, C., Lemery-Chalfant, K., Swanson, J., \& Reiser, M. (2008). Prediction of children's academic competence from their effortful control, relationships, and classroom participation. Journal of Educational Psychology, 100, 67-77.

van Ijzendoorn, M., Schuengel, C., \& Bakermans-Kranenburg, M. (1999). Disorganized attachment in early childhood: Meta-analysis of precursors, concomitants, and sequelae. Development and Psychopathology, 11(2), 225-249.

von Bertalanffy, L. (1975). Perspectives on general system theory. New York: Braziller. Voisin, D., Salazar, L., Crosby, R., Diclemente, R., Yarber, W., \& Staples-Horn, M. (2005). Teacher connectedness and health-related outcomes among detained adolescents. Journal of Adolescent health, 337, 17-23. 
Voisin, D., DiClemente, R., Salazar, L., Crosby, R., \& Yarber, W. (2006). Ecological factors associated with STD risk behaviors among detained female adolescents. Social Work, 51(1), 71-79.

Walter, U., \& Petr, C. (2007). Residential treatment: A review of the national literature. Lawrence, KS: University of Kansas School of Social Work.

Wells, K. (1991). Placement of emotionally disturbed children in residential treatment: A review of placement. American Journal of Orthopsychiatry, 61(3), 339.

Wentzel, K. (2002). Are effective teachers like good parents? Teaching styles and student adjustment in early adolescence. Child Development, 73(1), 287-301.

Wentzel, K. (1998). Social relationships and motivation in middle school: The role of parents, teachers, and peers. Journal of Educational Psychology, 90(2), 202-209.

Westen, D., Nakash, O., Thomas, C., Bradley, R. (2006). Clinical assessment of attachment patterns and personality disorder in adolescents and adults. Journal of Consulting and Clinical Psychology, 74, 1065-1085.

Whittaker, J. (2000). Reinventing residential childcare: An agenda for research and practice. Residential Treatment for Children \& Youth, 17(3), 13-30.

Wilson, P., \& Tan, G. (2004). Singapore teachers' personal and general efficacy for teaching primary social studies. International Research in Geographical and Environmental Education, 13, 209-222.

Yeo, L., Ang, R., Chong, W., Huan, V., \& Quek, C. (2008). Teacher efficacy in the Context of teaching low achieving students. Current Psychology, 27(3), 192-204.

Zimmerman, B. (1990, Winter90). Self-Regulated Learning and Academic Achievement: An Overview. Educational Psychologist, 25(1), 3-17. 
Zimmerman, B., Bandura, A., \& Martinez-Pons, M. (1992). Self-motivation for academic attainment: The role of self-efficacy beliefs and personal goal setting. American Educational Research Journal, 29(3), 663-676. 


\section{CURRICULUM VITAE}

\section{ANDREW J. NICHOLS M.C.}

Office:

Unit F2

Greystone Park Psychiatric Hospital

59 Koch Avenue

Morris Plain, NJ 07950

973-538-1800 ext. 4996

andrew.nichols@dhs.state.nj.us
Home:

$5994^{\text {th }}$ Avenue

Apt. 5B

Brooklyn, NY 11215

502-424-6018

\section{EDUCATIONAL HISTORY}

2007 - Present

August 2007

May 2002
Doctoral Candidate, Counseling Psychology

Department of Educational and Counseling Psychology

College of Education and Human Development

University of Louisville, Louisville, KY

Predicted Graduation Date: 2011

Dissertation Topic: An Analysis of Teacher Efficacy, Resident Efficacy, and Teacher-Student Relationships with Behaviorally Challenged Youth in Residential Treatment Settings.

Master of Counseling, Mental Health Counseling

College of Health and Human Services

University of Phoenix - Utah Campus, Salt Lake City, UT

Bachelor of Science, Summa cum Laude, Behavioral Science with Psychology Emphasis

School of Humanities, Arts, and Social Sciences

Utah Valley University, Orem, UT

Senior Independent Research Project: A Sociological-Based

Examination of Self-Esteem Development among At-Risk

Adolescents within Adjudicated and Private Pay Settings. 


\section{ACADEMIC HONORS}

2001

Outstanding Student of the Year

School of Humanities, Arts, and Social Sciences

Utah Valley University

2001

Discretionary Scholarship for Academic Achievement

School of Humanities, Arts, and Social Sciences

Utah Valley University

$2000-2002$

Dean's List, Utah Valley University

\section{SUPERVIZED CLINICAL EXPERIENCE}

$2009-2010$

Public Inpatient Psychiatric Hospital Practicum

Central State Hospital, Psychology Department, Louisville, KY

Supervised by Drs. Russell Williams and Susan Brittain

Responsibilities: Administer a broad range of intelligence, memory, personality, socio-emotional, suicide assessment, neurological, and forensic instruments/interviews. Integrate data into comprehensive psychological reports to augment treatment planning, psychiatric intervention, court proceedings, and postdischarge intervention/support. Participate in treatment planning meetings. Provide short and medium-term therapy to a culturally and racially diverse patient population, most of who are diagnosed as severely mentally ill.

University Counseling Center Assessment Practicum University of Louisville Counseling Center, Louisville, KY Supervised by Dr. Terri White

Responsibilities: Administered intelligence, achievement, neurological, socio-emotional, and computer assisted instruments to a diverse group of students aged nineteen to fifty. Integrated data into comprehensive psychological reports which specifically addressed learning disabilities and ADHD. Conducted in-depth background interviews and interpreted results to clients. 


\section{SUPERVIZED CLINICAL EXPERIENCE (continued)}

$2008-2009$

Community Mental Health Agency Practicum

Seven Counties Services, Inc., Crum's Lane Office, Louisville, KY

Supervised by Dr. Jeff Hicks

Responsibilities: Provided medium and long-term individual, family, and group therapy to an economically, ethnically and culturally diverse client population. Clients ranged from seven to sixty-four years of age. Clients presented with a broad range of medical, financial, and familial support issues. Conducted intake interviews, contributed to treatment planning meetings, and carried a caseload of 15 individuals/families. Completed detailed treatment notes which were often audited for outcome-based compliancy per Medicaid regulations. Consulted with multiple school and community resources to provide proactive case management benefits for clients in their home and school settings.

Community Mental Health Center Practicum Archdiocese of Louisville, Family Ministries Counseling Center Supervised by Dr. Kathleen Kirby

Responsibilities: Provided individual, family, and couples therapy to an ethnically and economically diverse client population. Many clients were immigrants and/or refugees from outside of the United States. Clients ranged from sixteen to sixty-seven years of age.

Systematic Treatment of Autism and Related Disorders (STAR)

STAR Summer Program, Louisville, KY

Supervised by Grace Mathai, M.A., Licensed Psychological Associate and Dr. Kathleen Kirby.

Responsibilities: Provided individual and group social skills training to children and adolescents diagnosed with Autism Spectrum Disorder; counseled family members in relation to successful behavioral interventions; contributed to students' longterm treatment plans. 
SUPERVIZED CLINICAL EXPERIENCE (continued)

$2007-2008$

Forensic Psychological Assessment Practicum

Private Practice of Dr. Dennis Wagner, Louisville, KY

Responsibilities: Completed comprehensive psychological assessments for a wide range of clients including sexual perpetrators, individuals presenting with Axis II features, and those suffering from learning disabilities. Administered intelligence, achievement, memory, personality, and socio-emotional instruments. Utilized semi-structured interviews. Worked with a diverse array of children, adolescents, and adults aged five to thirty four. Integrated data into full psychological reports which were utilized in court proceedings. Reported results to caseworkers, therapists, parents, and clients.

$2006-2007$

\section{Clinical Boarding School Practicum}

The Oakley School, Oakley, UT

Supervised by Dr. Robert Simmons and Rod Andrus M.S.W. LCSW

Responsibilities: Provided weekly individual and family therapy to a caseload of five adolescents. Structured and led two weekly process groups for students presenting with severe behavioral issues. Designed and implemented weekly experiential-therapy outings in either a wilderness or community service context for students presenting with severe behavioral issues. Attended weekly treatment planning meetings.

\section{PROFESSIONAL EXPERIENCE}

Over ten years experience working at the Oakley School, a clinical boarding school for adolescents designed to provide comprehensive therapeutic services in conjunction with academic and social development. While the average length of stay is one year, reintegration with students' families and/or the development of independent young adult living skills are the program's primary outcome goals.

$2002-2007 \quad$ Director of Experiential Education

The Oakley School, Oakley, UT

Responsibilities: This was an administrative position as one of five directors in a clinical boarding school with over 120 employees. Direct supervisory responsibilities included hiring, training, and mentoring a staff of 12 to work with adolescents presenting with a wide array of Axis I \& II behavioral issues. Other duties included design and implementation of experiential therapy-based (outdoor 
$1998-2002$

adventure, community service, and fine arts) curricula, assessment of programmatic outcomes via a qualitative rubric, college guidance and counseling to students, and providing wildernessbased therapeutic interventions for students presenting with severe behavioral issues.

\section{Experiential Education Specialist}

The Oakley School, Oakley, UT

Designed and instructed experiential courses in Rock-Climbing, Backcountry Skiing, Mountain Biking, Snowboarding, Mountaineering, and Community Service. My Community Service courses emphasized human interaction such as tutoring poverty level elementary students in an ESL setting, volunteering at women's and children's detoxification centers, and assisting adaptive ski programs.

\section{TEACHING EXPERIENCE}

2009-2010

Instructor

Department of Educational and Counseling Psychology

College of Education and Human Development

University of Louisville

Course Taught: Learning Theory and Human Growth and Development (Graduate)

Course Focus: Basic principles of learning theory and human development. Major theories of learning along with physical, social, cognitive, emotional, language, and cultural development as they apply to children and youth including those with special needs.

2008-2009

Instructor

Department of Teaching and Learning

College of Education and Human Development

University of Louisville

Course Taught: Human Development and Learning (Undergraduate)

Course Focus: Introduction to the basic principles of human development and learning as applied to home and school settings of children from birth to adolescence. 


\section{RESEARCH AND GRANT EXPERIENCES}

The Risking Connection Program: A Comprehensive Examination of Teacher and Student Relationships and Behaviors, Co-Writer/Investigator, 2009; Awarded \$3905 (Internal Research Initiation Grant, University of Louisville)

2007-Present

Graduate Research Assistant

Department of Teaching \& Learning

University of Louisville, Louisville, KY

Research Mentor: Nicole Fenty, Ph.D.

Responsibilities: Assisting faculty with all aspects of quantitative and qualitative research concerning the evaluation of special education populations, attention span to reading difficulties, and technology-enhanced teaching. Administered reading assessments to subjects with severe developmental disabilities.

2007-2009

Research Team Member

Department of Educational and Counseling Psychology University of Louisville, Louisville, KY

Research Mentor: Dr. Patrick Hardesty, Ph.D.

Responsibilities: Contributed to several research projects investigating school violence prevention, college career counseling to minorities, and career counseling center administration. Coauthored conference proposals and a book chapter.

2007-2008

\section{Graduate Research Assistant}

Department of Teaching \& Learning University of Louisville, Louisville, KY

Research Mentor: Shelley Thomas, Ph.D.

Responsibilities: Assisting faculty with all aspects of quantitative and qualitative research concerning culturally responsive pedagogy and alternative social studies education.

\section{SUBMITTED CHAPTER}

Hardesty, P. \& Nichols, A. (submitted). The integration of career development with minority identity. In Sandhu, D.S., Hudson, J.B., \& Taylor-Archer, M. (Eds., in progress). Handbook of diversity in higher education. Huntington, NY: Nova Science. 


\section{POSTERS/PRESENTATIONS}

Valentine, J. C., Burnett, J. B., Nichols, A., Gonshak, A. B., Tong, S., Whitten, M., \& Pickering, M. (2009). Validity characteristics of randomized and quasi-experiments in studies of school-based prevention programs. Poster presented at the 2009 American Psychological Association Annual Convention, Toronto.

Mitchell, N. G., Wyrick, A. J., Nichols, A. J., Carrier, J. W., Banister, A. B. (2008, August). Social stigmatization of obesity in African American preschool children. Poster presented at the 2008 American Psychological Association Annual Convention, Boston, MA.

Nichols, A., Phillips, I., Bulloch, M., \& Meyer, J. (2004). Holistically balancing treatment interventions for students transitioning from wilderness settings to clinical boarding schools. Presented at the National Association of Therapeutic Schools and Programs (NATSAP) Fourth Annual Utah Regional Conference, Oakley, Utah.

Nichols, A. \& Yells, D. P. (2002). An examination of self-esteem development among adolescents enrolled at an emotional growth boarding school. Poster presented at the Rocky Mountain Psychological Association Conference in Park City, UT.

\section{MANUSCRIPTS IN PREPARATION}

Hardesty, P., \& Nichols, A. A systematic survey and examination of practices within college/university career counseling centers: Are services under-represented and under-utilized for special needs and minority groups.

Valentine, J. C., Burnett, J. B., Nichols, A., Gonshak, A. B., Tong, S., Whitten, M., \& Pickering, M. An examination of validity characteristics of randomized and quasiexperiments in studies of school-based prevention programs.

\section{PROFESSIONAL SERVICE}

2009 - Present

Head Graduate Assistant

Department of Teaching \& Learning

University of Louisville, Louisville, $\mathrm{KY}$

Supervisor: Dr. Ann Larson, Vice Dean, Acting Chair and

Professor

Responsibilities: Assist with interviewing and selection of graduate students, undergraduate students, and graduate assistants. Coordinate communication and scheduling between graduate assistants. Provide mentoring/training to graduate teaching instructors. 
Responsibilities: Collaborated with faculty members and other doctoral students on program and policy changes and student issues.

\section{ASSOCIATION MEMBERSHIPS}

American Psychological Association

Kentucky Psychological Association

Association for Experiential Education (Inactive)

National Association of Therapeutic Schools and Programs (Inactive) 